\title{
Energy and Environmental Research Emphasizing Low-Rank Coal -- Task 2.4 Air Toxic Fine Particulate Control
}

\section{Topical Report}

Grant E. Dunham

Marlys K. Heidt

Stanley J. Miller

March 1995

Work Performed Under Contract No.: DE-FC21-93MC30097

For

U.S. Department of Energy

Office of Fossil Energy

Morgantown Energy Technology Center

Morgantown, West Virginia

By

University of North Dakota

Grand Forks, North Dakota 


\section{DISCLAIMER}

This report was prepared as an account of work sponsored by an agency of the United States Government. Neither the United States Government nor any agency thereof, nor any of their employees, makes any warranty, express or implied, or assumes any legal liability or responsibility for the accuracy, completeness, or usefulness of any information, apparatus, product, or process disclosed, or represents that its use would not infringe privately owned rights. Reference herein to any specific commercial product, process, or service by trade name, trademark, manufacturer, or otherwise does not necessarily constitute or imply its endorsement, recommendation, or favoring by the United States Government or any agency thereof. The views and opinions of authors expressed herein do not necessarily state or reflect those of the United States Government or any agency thereof.

This report has been reproduced directly from the best available copy.

Available to DOE and DOE contractors from the Office of Scientific and Technical Information, 175 Oak Ridge Turnpike, Oak Ridge, TN 37831; prices available at (615) 576-8401.

Available to the public from the National Technical Information Service, U.S. Department of Commerce, 5285 Port Royal Road, Springfield, VA 22161; phone orders accepted at (703) 487-4650. 


\section{Energy and Environmental Research Emphasizing Low-Rank Coal -- Task 2.4 Air Toxic Fine Particulate Control}

\section{Topical Report}

Grant E. Dunham

Marlys K. Heidt

Stanley J. Miller

Work Performed Under Contract No.: DE-FC21-93MC30097

\section{For}

U.S. Department of Energy

Office of Fossil Energy

Morgantown Energy Technology Center

P.O. Box 880

Morgantown, West Virginia 26507-0880

By

University of North Dakota

Energy and Environmental Research Center

P.O. Box 9018

Grand Forks, North Dakota 58202-9018 


\section{ACKNOWLEDGMENT}

This final topical report was prepared with the support of the U.S. Department of Energy (DOE) Morgantown Energy Technology Center Cooperative Agreement No. DE-FCं21-93MC30097. However, any opinions, findings, conclusions, or recommendations expressed herein are those of the author(s) and do not necessarily reflect the views of the DOE.

\section{EERC DISCLAIMER}

"LEGAL NOTICE: This research report was prepared by the Energy \& Environmental Research Center (EERC), an agency of the University of North Dakota, as an account of work sponsored by the U.S. Department of Energy. Because of the research nature of the work performed, neither the EERC nor any of its employees makes any warranty, express or implied, or assumes any legal liability or responsibility for the accuracy, completeness, or usefulness of any information, apparatus, product, or process disclosed, or represents that its use would not infringe privately owned rights. Reference herein to any specific commercial product, process, or service by trade name, trademark, manufacturer, or otherwise does not necessarily constitute or imply its endorsement or recommendation by the EERC." 


\section{TABLE OF CONTENTS}

LIST OF FIGURES $\ldots \ldots \ldots \ldots \ldots \ldots \ldots \ldots \ldots \ldots \ldots \ldots \ldots \ldots \ldots$

LIST OF TABLES $\ldots \ldots \ldots \ldots \ldots \ldots \ldots \ldots \ldots \ldots \ldots \ldots \ldots \ldots \ldots$

EXECUTIVE SUMMARY $\ldots \ldots \ldots \ldots \ldots \ldots \ldots \ldots \ldots \ldots \ldots \ldots \ldots \ldots \ldots$

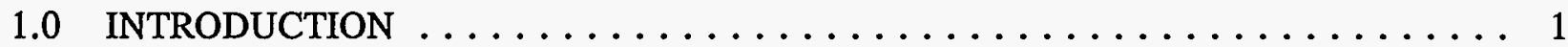

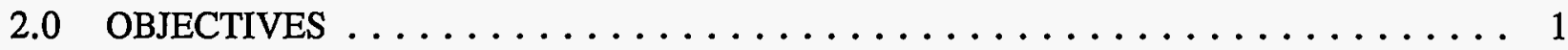

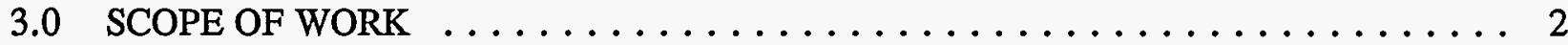

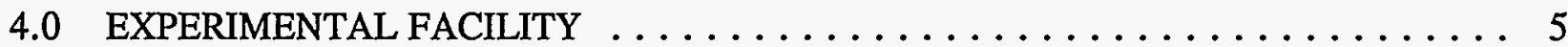

5.0 ACCOMPLISHMENTS/RESULTS $\ldots \ldots \ldots \ldots \ldots \ldots \ldots \ldots \ldots \ldots$

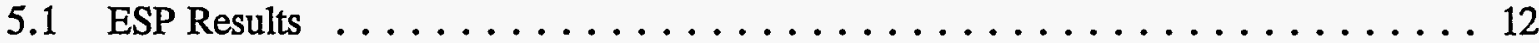

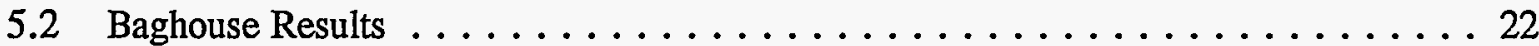

6.0 CONCLUSIONS/RECOMMENDATIONS $\ldots \ldots \ldots \ldots \ldots \ldots \ldots$ 


\section{LIST OF FIGURES}

1 Tensile strengths of selected ashes: Big Brown baseline (PTC-BB-386), Absaloka (PTC-AB-445), conditioned Big Brown (PTC-BB-384), and Blacksville (PTC-BV-473) . . . 5

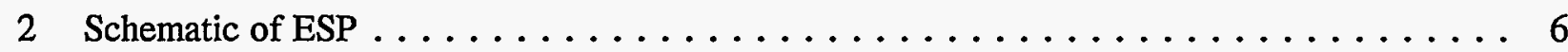

3 Schematic of PTC pulse-jet baghouse $\ldots \ldots \ldots \ldots \ldots \ldots \ldots \ldots \ldots \ldots \ldots \ldots \ldots \ldots$

4 Schematic of particulate sampling equipment $\ldots \ldots \ldots \ldots \ldots \ldots \ldots$

5 Combined multicyclone/Coulter counter size distribution for Absaloka ash . . . . . . . . 9

6 Combined multicyclone/Coulter counter size distribution for conditioned Big Brown ash . . . 10

7 Combined multicyclone/Coulter counter size distribution for Big Brown ash . . . . . . . 10

8 Combined multicyclone/Coulter counter size distribution for Blacksville ash . . . . . . . 11

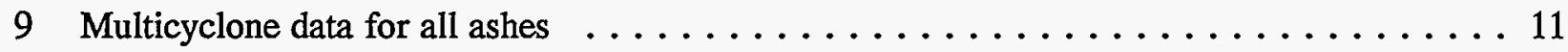

10 Multicyclone data for original and redispersed Big Brown ash . . . . . . . . . . . 12

11 Combined inlet and after-ESP-cleaning SMPS/APS size distributions for conditioned

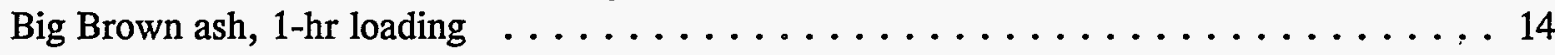

12 Combined inlet and after-ESP-cleaning SMPS/APS size distributions for conditioned Big Brown ash, 15 -min loading . . . . . . . . . . . . . . . . . 14

13 Ratio of after-ESP-plate-cleaning concentration to inlet concentration, based on the combined SMPS/APS data, 1 -hr loading, Absaloka ash . . . . . . . . . . . 17

14 Ratio of after-ESP-plate-cleaning concentration to inlet concentration, based on the combined SMPS/APS data, 15-min loading, Absaloka ash . . . . . . . . . . 17

15 Ratio of after-ESP-plate-cleaning concentration to inlet concentration, based on the combined SMPS/APS data, 1-hr loading, conditioned Big Brown ash . . . . . . . 18

16 Ratio of after-ESP-plate-cleaning concentration to inlet concentration, based on the combined SMPS/APS data, 15-min loading, conditioned Big Brown ash . . . . . . . 18

17 Ratio of after-ESP-plate-cleaning concentration to inlet concentration, based on the combined SMPS/APS data, 1 -hr loading, Big Brown ash . . . . . . . . . . . . 19

Continued . . 


\section{LIST OF FIGURES (Continued)}

18 Ratio of after-ESP-plate-cleaning concentration to inlet concentration, based on the combined SMPS/APS data, 15-min loading, Big Brown ash . . . . . . . . . . . . . . 19

19 Ratio of after-ESP-plate-cleaning concentration to inlet concentration, based on the combined SMPS/APS data, 1-hr loading, Blacksville ash . . . . . . . . . . . . 20

20 Ratio of after-ESP-plate-cleaning concentration to inlet concentration, based on the combined SMPS/APS data, 15 -min loading, Blacksville ash . . . . . . . . . . 20

21 Ratio of after-ESP-plate-cleaning concentration to inlet concentration as a function of time, based on APS data, 1-hr loading, Absaloka ash . . . . . . . . . . . . . . 21

22 Ratio of after-pulse-jet-cleaning concentration to inlet concentration, based on the combined SMPS/APS data, 7-in. W.C., 60-psig pulse pressure, Absaloka ash . . . . . . . 25

23 Ratio of after-pulse-jet-bag-cleaning concentration to inlet concentration, based on the combined SMPS/APS data, 7-in. W.C., 20-psig pulse pressure, Absaloka ash . . . . . 25

24 Ratio of after-pulse-jet-bag-cleaning concentration to inlet concentration, based on the combined SMPS/APS data, 2-in. W.C., 60-psig pulse pressure, Absaloka ash . . . . . 26

25 Ratio of after-pulse-jet-bag-cleaning concentration to inlet concentration, based on the combined SMPS/APS data, 2-in. W.C., 20-psig pulse pressure, Absaloka ash . . . . . . 26

26 Ratio of after-pulse-jet-bag-cleaning concentration to inlet concentration, based on the combined SMPS/APS data, 7-in. W.C., 60-psig pulse pressure, baseline Big Brown ash . . . 27

27 Ratio of after-pulse-jet-bag-cleaning concentration to inlet concentration, based on the combined SMPS/APS data, 7-in. W.C., 20-psig pulse pressure, baseline Big Brown ash . . . 27

28 Ratio of after-pulse-jet-bag-cleaning concentration to inlet concentration, based on the combined SMPS/APS data, 7-in. W.C., 60-psig pulse pressure, conditioned

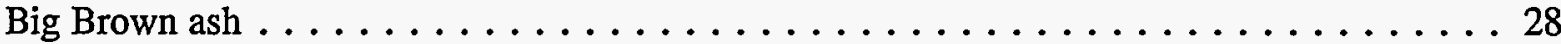

29 Ratio of after-pulse-jet-bag-cleaning concentration to inlet concentration, based on the combined SMPS/APS data, 7-in. W.C., 20-psig pulse pressure, conditioned Big

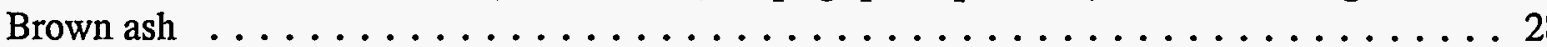

30 Ratio of after-pulse-jet-bag-cleaning concentration to inlet concentration, based on the combined SMPS/APS data, 7-in. W.C., 60-psig pulse pressure, Blacksville ash . . . . . 29

31 Ratio of after-pulse-jet-bag-cleaning concentration to inlet concentration, based on the combined SMPS/APS data, 7-in. W.C., 20-psig pulse pressure, Blacksville ash . . . . . 29 


\section{LIST OF TABLES}

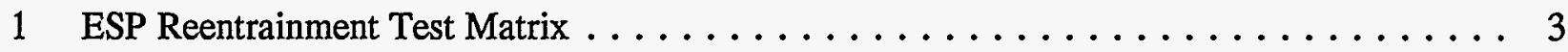

2 Pulse-Jet Fabric Filter Reentrainment Test Matrix $\ldots \ldots \ldots \ldots \ldots \ldots$

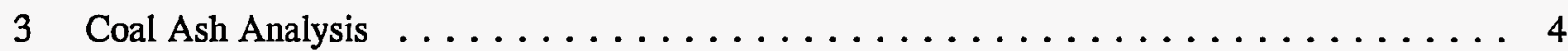

4 ESP Mass Balance Data . . . . . . . . . . . . . . . . . . . . . 13

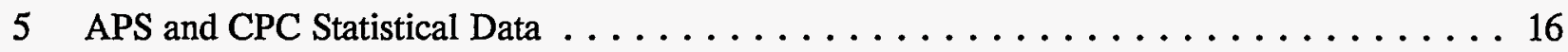

6 Baghouse Mass Balance Data $\ldots \ldots \ldots \ldots \ldots \ldots \ldots \ldots \ldots \ldots \ldots \ldots \ldots \ldots$

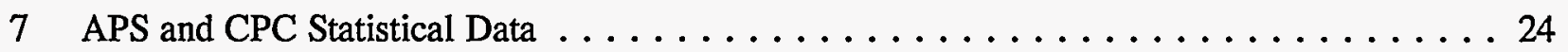




\section{TASK 2.4 AIR TOXIC FINE PARTICULATE CONTROL}

\section{EXECUTIVE SUMMARY}

Significant concerns exist over the impact of increasing energy consumption on ambient air quality. Acid rain and the passage of legislation to reduce emission of acid rain precursors continue to be prominent issues in the United States, Canada, Europe, and Japan. Emission of fine particles is of concern because these particles can be deposited in the lower respiratory system through normal breathing. The potential problem is further compounded because hazardous trace elements, such as selenium and arsenic, are known to be concentrated on such fine particles. In addition to potentially causing adverse health effects, fine particles, including secondary sulfates, are the primary cause of visibility impairment in the atmosphere. The 1990 Clean Air Act Amendments address the issue of emission of acid rain precursors, require the study of air toxic emissions, and provide for possible expansion of visibility protection measures. Therefore, a current need exists to develop superior, but economical, methods to control emission of $\mathrm{SO}_{2}, \mathrm{NO}_{x}$, fine particles, and air toxics.

Emission from coal-fired boilers is an issue because of the current concern over atmospheric air toxics, which contain high concentrations of trace elements. The best method of minimizing the emission of these air toxic trace elements to the atmosphere is to install high-efficiency fine-particle control devices. After collection, the dust must be removed from the filter bags or electrostatic precipitator (ESP) plates and transferred to the hopper without significant redispersion. Since it is more difficult to collect fine particles, the extent to which the dust is redispersed into its original particle-size distribution will have a major impact on the overall fine-particle collection efficiency of the filter or ESP and, subsequently, the collection efficiency of air toxic metals. Previous research has shown that the collectability of fine particles from coal combustion is highly dependent on the cohesive properties of the fly ash. Cohesive properties are also important in dust cake release, rapping or pulsing reentrainment, and hopper reentrainment.

The goal of Task 2.4 was to evaluate redispersion of dust in particulate control devices so that the appropriate methods to minimize redispersion can be implemented. The primary objective was to determine the extent that fly ash is redispersed as individual particles upon cleaning of the filters or ESP plates. The current research was to determine if the level of redispersion of fly ash correlates with measurable cohesive dust properties. This will contribute to the long-term project goal of developing models to the point where they can be used to help design particulate control devices for the lowest level of fine-particle emissions at a reasonable cost.

The approach was to evaluate several variables and their effects on the amount and the size distribution of ash redispersed when a filter or ESP plate is cleaned. Three independent variables were chosen for the reentrainment tests: ash layer thickness, ash type, and cleaning energy. The dependent variables that were used to determine the effects of the ash layer thickness, cleaning energy and ash type included the size distribution of the injected ash, the size distribution of the ash after cleaning the ESP plate or filter, the concentration of particles in the submicron size range for both the inlet ash and the ash redispersed when cleaning the ESP plate or filter, and the cohesive properties of the ash.

The ESP reentrainment tests were performed with the ESP on the particulate test combustor (PTC) at the Energy \& Environmental Research Center. The baghouse reentrainment tests were 
performed with the three-bag pulse-jet baghouse on the PTC. A single Ryton bag 13 feet long and 6 inches in diameter was installed in the baghouse.

Although it was possible to redisperse the ash into the submicron region, it appears the injection system was not capable of redispersing the ashes to different size distributions. The tensile strength measurements indicate the ashes should have-behaved differently. For the ESP reentrainment tests, no effect is apparent on the size distribution or concentration of submicron particles due to ash type. This may be a limitation of the ash injection system. The data do indicate the ash was redispersed as larger particles when the ESP plate was rapped, most likely because of the agglomeration of smaller particles that did not redisperse when the plate was rapped. However, a difference due to ash layer thickness does appear to exist. The thicker ash layer redispersed to a larger size distribution than that from the thinner ash layer. The mass balance data indicated the ash with the highest tensile strength (Blacksville) was the easiest to remove from the plate and the ash with the lowest tensile strength (baseline Big Brown) was the most difficult. The comparison of inlet particulate concentrations to concentrations after rapping the ESP plate indicates the ash was redispersed to concentrations lower than those in the inlet in the submicron region and higher than those in the inlet for larger particles. This indicates agglomeration of the smaller particles.

For the baghouse tests, the mass balance data again indicated the Blacksville ash was the easiest to remove and the baseline Big Brown ash was the most difficult, which is the opposite of that expected based on the tensile strength data. Based on the mass median diameter data, the Absaloka and the baseline and conditioned Big Brown ashes were redispersed to smaller size distributions than the inlet ash. However, the comparison of inlet particulate concentrations to those obtained after pulsing the bags indicate the ash was redispersed to concentrations lower than those in the inlet in the submicron region and near inlet levels for larger particles. This again indicates agglomeration of the smaller particles.

Overall the results were inconclusive. A different method should be employed to determine the effect of ash type on redispersion. Pilot-scale tests could be conducted with the original ash as it is generated; then no question of redispersing the ash to its original size distribution upon injection would exist. Also, the conditioned ash would retain its higher tensile strength. A method to determine the amount of ash suspended in the collection device chamber upon cleaning must also be developed for a complete mass balance. It is not possible to correlate these results with the tensile strength data to develop a model of ash redispersion upon collection device cleaning. Also, the data collected by testing the ash type, ash layer thickness, and cleaning energy did not provide any useful information for developing a model of ash redispersion. 


\section{TASK 2.4 AIR TOXIC FINE PARTICULATE CONTROL}

\subsection{INTRODUCTION}

Significant concerns exist over the impact of increasing energy consumption on ambient air quality. Acid rain and the passage of legislation to reduce emission of acid rain precursors continue to be prominent issues in the United States, Canada, Europe, and Japan. Emission of fine particles is concern because these particles can be deposited in the lower respiratory system through normal breathing. The potential problem is further compounded because hazardous trace elements, such as selenium and arsenic, are known to be concentrated on such fine particles. Recent studies indicate that current levels of fine particles in the atmosphere cause up to 60,000 excess deaths per year and the current ambient air quality standard for PM10 may not adequately protect public health. In addition to potentially causing adverse health effects, fine particles, including secondary sulfates, are the primary cause of visibility impairment in the atmosphere. The 1990 Clean Air Act Amendments address the issue of emission of acid rain precursors, require the study of air toxic emissions, and provide for possible expansion of visibility protection measures. Therefore, a current need exists to develop superior, but economical, methods to control emission of $\mathrm{SO}_{2}, \mathrm{NO}_{x}$, fine particles, and air toxics.

Previous research at the Energy \& Environmental Research Center (EERC) has focused on two areas: 1) bench-scale efforts to investigate the relationship between fine-particle emission from fabric filters and electrostatic precipitators (ESPs) and the cohesive properties of fly ash and 2) investigation of the impact of coal combustion on atmospheric visibility. Control of fine-particle emission from coal-fired boilers is an issue because of the current concern over atmospheric air toxics, which contain high concentrations of trace elements. The best method of minimizing the emission of these air toxic trace elements to the atmosphere is to install high-efficiency fine-particle control devices. After collection, the dust must be removed from the filter bags or ESP plates and transferred to the hopper without significant redispersion. Since it is more difficult to collect fine particles, the extent to which the dust is redispersed into its original particle-size distribution will have a major impact on the overall fine-particle collection efficiency of the filter or ESP and, subsequently, the collection efficiency of air toxic metals. The application is not only to conventional particulate control technologies such as fabric filters and ESPs, but also to advanced filtration methods such as the CeraMem ${ }^{\otimes}$ ceramic filter and ceramic candle filters. Previous research has shown that the collectability of fine particles from coal combustion is highly dependent on the cohesive properties of the fly ash. Cohesive properties are also important in dust cake release, rapping or pulsing reentrainment, and hopper reentrainment.

\subsection{OBJECTIVES}

The goal of Task 2.4 was to evaluate redispersion of dust in particulate control devices so that the appropriate methods to minimize redispersion could be implemented. The primary objective was to determine the extent that fly ash is redispersed as individual particles upon cleaning of the filters or ESP plates. Past research has focused on the development of reliable methods to measure the cohesive properties of fly ash in an effort to develop a model that relates cohesive properties to fineparticle emission. A secondary objective was to determine if the level of redispersion of fly ash correlated with measurable cohesive dust properties. The long-term project goal was to develop 
models to the point where they could be used to help design particulate control devices for the lowest level of fine-particle emission at a reasonable cost.

\subsection{SCOPE OF WORK}

The planned work consisted of bench-scale tests to determine the extent of fly ash redispersion upon cleaning the filters or ESP plates. The completed test matrices for the ESP and baghouse tests and the ambient conditions at the time of each test are presented in Tables 1 and 2. Because of delays in obtaining the CeraMem ${ }^{\otimes}$ filters, no reentrainment tests were completed on these filters. However, the filters are being tested under another program for ultrahigh particulate collection efficiency.

An ideal dust would readily release from the ESP plates upon rapping and fall to the hopper with minimum redispersion. In the worst-case scenario, ash would release from the ESP plates, be completely redispersed by the incoming flue gas and either be recollected on the ESP plates or carried out of the stack by the flue gas. A minimum cohesive or tensile strength would appear to be desirable to achieve good dust cake release, but to minimize redispersion of the dust into its original particle-size distribution, high dust tensile strength is preferred. Since these two factors are in direct opposition, a balance between good dust release and minimum redispersion must be achieved for optimum ESP performance.

For fabric filters, the cake should release from the fabric with a minimum energy input and without significant redispersion of the dust, while maintaining some minimum residual dust cake to achieve a high collection efficiency. Under nonideal conditions, the dust would release from the fabric, including the residual dust cake, and be redispersed to its original size distribution. Lacking a residual dust cake, the fine particles would pass through the bag, resulting in a very low collection efficiency for the fine particles. The relationship between dust redispersion and dust cohesive properties in fabric filters is analogous to that in an ESP. Low cohesive strength appears to facilitate good cake release and low residual dust cake thickness, while high cohesive strength seems necessary to maintain high dust cake porosity (low pressure drop) and prevent dust reentrainment upon cleaning. Obviously, a proper balance between these factors must be obtained to optimize particulate collection efficiency, pressure drop, and dust redispersion.

The level of reentrainment of submicron particles is important since they are the most difficult to collect and hazardous trace elements are known to be concentrated on such fine particles. The documentation and quantification of the level of reentrainment will help determine the importance of filtering parameters such as ash layer thickness, cleaning energy, and dust characteristics. This information can then be used to optimize the collection efficiency of the fine particles.

The approach was to look at several variables and their effects on the amount and size distribution of ash redispersed when cleaning a filter or ESP plate. Three independent variables were evaluated for the reentrainment tests: ash layer thickness, ash type, and cleaning energy. Ash layer thickness affects the amount of ash reentrained, but it may also affect the extent to which the ash is redispersed. A thicker ash layer may form larger agglomerates that will reach the hopper without 
TABLE 1

ESP Reentrainment Test Matrix

\begin{tabular}{|c|c|c|c|c|c|c|c|}
\hline Date & $\begin{array}{c}\text { Coal } \\
\text { Run No. }\end{array}$ & Ash Type & $\begin{array}{c}\text { Ash } \\
\text { Collection } \\
\text { Time, } \\
\text { min }\end{array}$ & $\begin{array}{c}\text { Relative } \\
\text { Humidity, \% }\end{array}$ & $\begin{array}{c}\text { ESP } \\
\text { Voltage, } \\
\text { kV }\end{array}$ & $\begin{array}{c}\text { Gas } \\
\text { Flow, } \\
\text { scfm }\end{array}$ & $\begin{array}{c}\text { Grain } \\
\text { Loading, } \\
\text { gr/scf }\end{array}$ \\
\hline $4 / 27 / 94$ & $A B-445$ & Absaloka & 15 & 11 & 55 & 129.8 & 6.1 \\
\hline $4 / 27 / 94$ & BB-386 & Big Brown (baseline) & 15 & 14 & 55 & 129.8 & 6.3 \\
\hline $4 / 28 / 94$ & BB-386 & Big Brown (baseline) & 60 & 14 & 55 & 130.3 & 5.9 \\
\hline $4 / 28 / 94$ & $A B-445$ & Absaloka & 60 & 14 & 55 & 130.4 & 5.6 \\
\hline $4 / 29 / 94$ & BB-384 & Big Brown (conditioned) & 60 & 14 & 55 & 130.1 & 6.7 \\
\hline $4 / 29 / 94$ & BB-384 & Big Brown (conditioned) & 15 & 16 & 55 & 130.1 & 6.5 \\
\hline $6 / 02 / 94$ & BV -473 & Blacksville & 60 & 19 & 55 & 130.1 & 5.9 \\
\hline $6 / 13 / 94$ & BV -473 & Blacksville & 15 & 41 & 55 & 129.8 & 4.9 \\
\hline
\end{tabular}

TABLE 2

Pulse-Jet Fabric Filter Reentrainment Test Matrix

\begin{tabular}{|c|c|c|c|c|c|c|}
\hline Date & $\begin{array}{c}\text { Coal } \\
\text { Run No. }\end{array}$ & Ash Type & $\begin{array}{c}\text { Relative } \\
\text { Humidity, \% }\end{array}$ & Fabric & $\begin{array}{c}\text { Nominal } \\
\text { Pressure } \\
\text { Drop, in. } \mathrm{H}_{2} \mathrm{O}\end{array}$ & $\begin{array}{c}\text { Cleaning } \\
\text { Energy, } \\
\text { psig }\end{array}$ \\
\hline $6 / 21 / 94$ & $A B-445$ & Absaloka & 35 & Ryton & 7 & 20 \\
\hline $6 / 22 / 94$ & $A B-445$ & Absaloka & 59 & Ryton & 7 & 20 \\
\hline $6 / 22 / 94$ & $A B-445$ & Absaloka & 54 & Ryton & 2 & 60 \\
\hline $6 / 22 / 94$ & $\mathrm{AB}-445$ & Absaloka & 55 & Ryton & 2 & 60 \\
\hline $6 / 23 / 94$ & $\mathrm{BB}-386$ & Big Brown (baseline) & 36 & Ryton & 7 & 20 \\
\hline $6 / 24 / 94$ & BV -473 & Blacksville & 50 & Ryton & 7 & 60 \\
\hline $6 / 24 / 94$ & $\mathrm{BV}-473$ & Blacksville & 45 & Ryton & 7 & 20 \\
\hline $7 / 06 / 94$ & BB-384 & Big Brown & 47 & Ryton & 7 & 60 \\
\hline $7 / 06 / 94$ & BB-384 & Big Brown & 50 & Ryton & 7 & 20 \\
\hline
\end{tabular}


being redispersed. Four fly ash samples were selected from our stored fly ash sample inventory, based on previous ESP and fabric filtration experiments at the EERC. The ashes evaluated included a Big Brown Texas lignite, a Big Brown Texas lignite conditioned with $\mathrm{SO}_{3}$ and ammonia, an Absaloka subbituminous coal ash, and a Blacksville bituminous coal ash. The results of coal ash $\mathrm{x}$-ray diffraction (XRD) analyses are given in Table 3. As shown in the table, the Blacksville coal had a much higher iron content (23.6\%) than either the Big Brown (4.5\%) or Absaloka (3.5\%) coals. Ashes with a range of cohesive properties were selected to evaluate their effect on dispersability or reentrainment. Tensile strength measurements for the ash samples are plotted as a function of porosity in Figure 1. Previous tensile strength measurements on similar ash samples showed that the Big Brown baseline (unconditioned) ash had the lowest measured cohesive tensile strength at constant porosity and the Big Brown conditioned ash had the highest tensile strength. The Absaloka and Blacksville ashes had intermediate tensile strengths. However, the current measurements show the Blacksville with the highest tensile strength (extrapolated). When the conditioned Big Brown ash container was opened, a strong smell of ammonia was evident, indicating the ash was no longer conditioned. This is also evidenced by the decreased tensile strength. Tests to determine the effect of cleaning energy were completed in the baghouse. Pulse pressures of 20 and 60 psig were used. Tests were also planned to determine the effect of cleaning energy intensity in the ESP, but the cleaning mechanism did not provide any adjustment.

The dependent variables used to determine the effects of the ash layer thickness, cleaning energy, and ash type included the size distribution of the injected ash, the size distribution of the ash after cleaning the ESP plate or filter, the concentration of particles in the submicron-size range for both the inlet ash and the ash redispersed when cleaning the ESP plate or filter, and the cohesive properties of the ash. The change in size distribution of the ash redispersed when the ESP plate or filter was cleaned was evaluated as a function of time.

TABLE 3

Coal Ash Analysis

\begin{tabular}{lccc}
\hline $\begin{array}{l}\text { Major Elements as Oxides, } \\
\text { wt\% on a dry basis }\end{array}$ & Absaloka & Blacksville & Big Brown \\
\hline $\mathrm{SiO}_{2}$ & 34.3 & 40.2 & 46.5 \\
$\mathrm{Al}_{2} \mathrm{O}_{3}$ & 20.3 & 18.8 & 15.7 \\
$\mathrm{Fe}_{2} \mathrm{O}_{3}$ & 3.5 & 23.6 & 4.5 \\
$\mathrm{TiO}_{2}$ & 1.0 & 0.8 & 1.9 \\
$\mathrm{P}_{2} \mathrm{O}_{5}$ & 2.6 & 0.7 & 0.3 \\
$\mathrm{CaO}$ & 14.2 & 7.3 & 17.6 \\
$\mathrm{MgO}_{\mathrm{Na}} \mathrm{O}$ & 6.7 & 0.7 & 3.5 \\
$\mathrm{~K}_{2} \mathrm{O}$ & 1.9 & 1.1 & 0.4 \\
$\mathrm{SO}_{3}$ & 0.6 & 1.1 & 0.4 \\
\hline
\end{tabular}




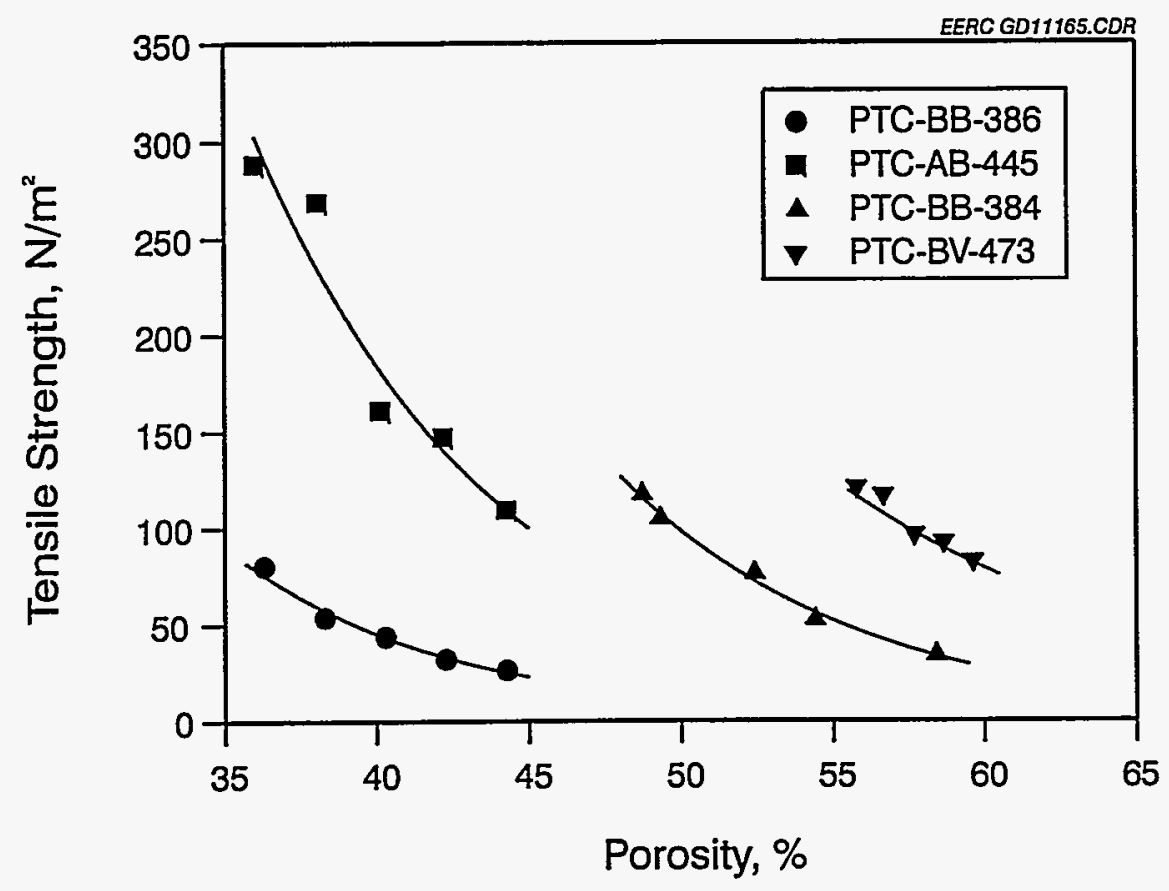

Figure 1. Tensile strengths of selected ashes: Big Brown baseline (PTC-BB-386), Absaloka (PTCAB-445), conditioned Big Brown (PTC-BB-384), and Blacksville (PTC-BV-473).

\subsection{EXPERIMENTAL FACILITY}

The ESP reentrainment tests were performed with the ESP (Figure 2) on the particulate test combustor (PTC) at the EERC. The ESP has a single wire (one field) and an 8.6-ft-long by 11-in.diameter tubular plate. The nominal applied voltage was $55,000 \mathrm{~V}$ for all tests. The induced-draft fan for the combustor was used to maintain a nominal gas flow of $130 \mathrm{scfm}$, which translates to a nominal gas velocity of $3.3 \mathrm{ft} / \mathrm{sec}$ in the ESP.

The baghouse reentrainment tests were performed with the three-bag pulse-jet baghouse (Figure 3) on the PTC. A single Ryton bag, $13 \mathrm{ft}$ long and 6 in. in diameter, was installed in the baghouse. Blanks were installed in the remaining tube sheet holes. The pulse-jet chamber is $20 \mathrm{in}$. in diameter and $21 \mathrm{ft}$ long. The induced-draft fan for the combustor was used to maintain a nominal gas flow of $130 \mathrm{scfm}$, which translates to a nominal gas velocity of $0.99 \mathrm{ft} / \mathrm{sec}$ in the chamber.

An AccuRate dry material feeder and an eductor were used to feed ash into the inlet piping upstream of the ESP or the pulse-jet baghouse. A concern with using a dry material feeder was the ability to redisperse the ash into its original size distribution or into the submicron region. It was suspected that the van der Waal forces on the submicron particles would be too great, preventing them from being redispersed. However, results indicated the ashes were redispersed into the submicron region but not into their original size distributions. 


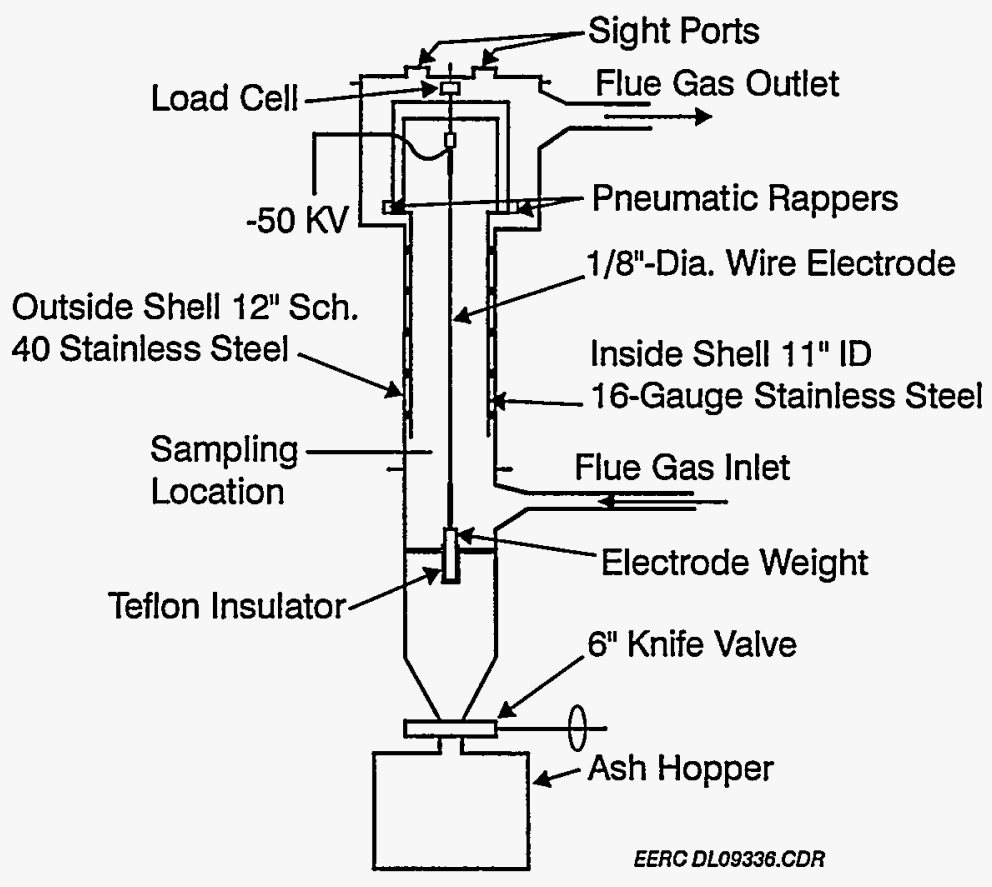

Figure 2. Schematic of ESP.

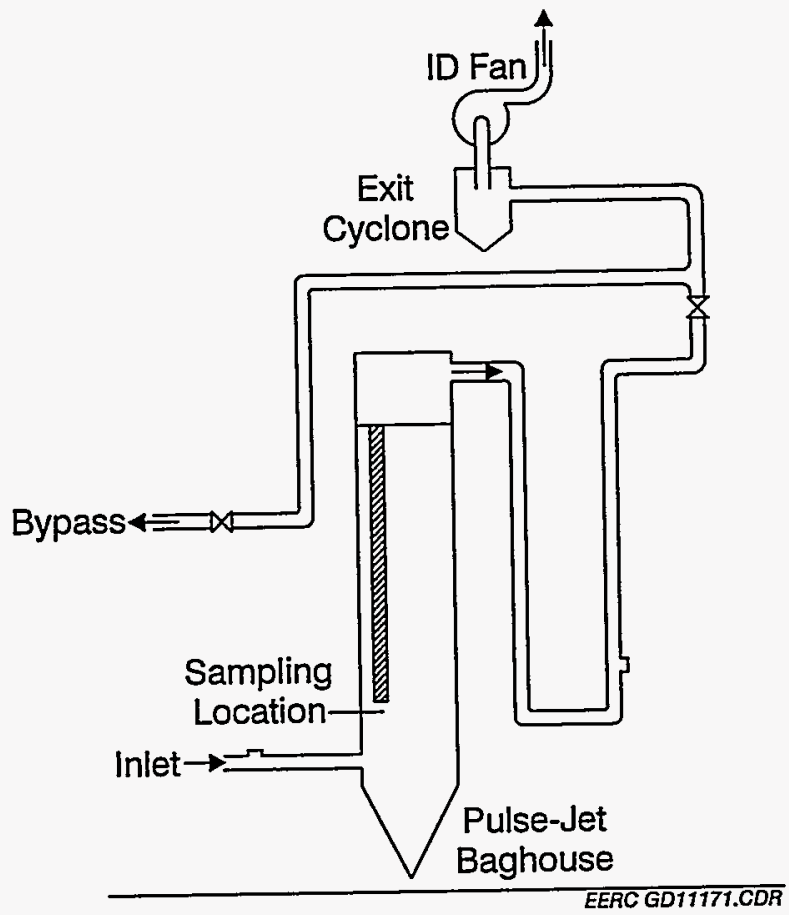

Figure 3. Schematic of PTC pulse-jet baghouse. 
To determine the effect of the ash layer thicknesses on redispersion, ash was injected upstream of the ESP for $15 \mathrm{~min}$ or 1 hour before cleaning. For the baghouse tests, ash was injected until the pressure drop across the bags had increased to either 2 or 7 in. W.C. Inlet sampling with a TSI Model 3934 scanning mobility particle sizer (SMPS), a TSI Model 33 aerodynamic particle sizer (APS), and a TSI Model 3022A condensation particle counter (CPC) was performed during the longer loading tests. Figure 4 is a diagram of the sampling system. The SMPS system measures the number size distribution of particles using an electrical mobility detection technique. The SMPS uses a bipolar charger in the electrostatic classifier to charge particles to a known charge distribution. The particles are then classified according to their ability to traverse an electrical field and counted with a CPC. The SMPS is capable of determining the size distribution of fine particles from 0.01 to $1.0 \mu \mathrm{m}$ in 90 seconds. The APS is a laser particle sizer used to characterize particles in the $0.5-30-\mu \mathrm{m}$ range. The APS also measures respirable mass, which is defined by the American Council of Governmental and Industrial Hygienists as a weighted sum of particles between 1 and $10 \mu \mathrm{m}$, with greater weighting given to the smaller particles. A CPC separate from the electrostatic classifier was used for continuous on-line monitoring of the total concentration of particles from 0.01 to $4.25 \mu \mathrm{m}$. The particles entering the CPC are detected and counted by an optical detector after a supersaturated vapor condenses onto the particles, causing them to grow into larger droplets. The range of detection is from less than 0.007 particles $/ \mathrm{cm}^{3}$ to $9.99 \times 10^{6}$ particles $/ \mathrm{cm}^{3}$.

For the ESP tests, the ash feed was turned off when the ash loading was completed. The induced-draft fan remained on for approximately 3 minutes to clear any ash remaining in the inlet

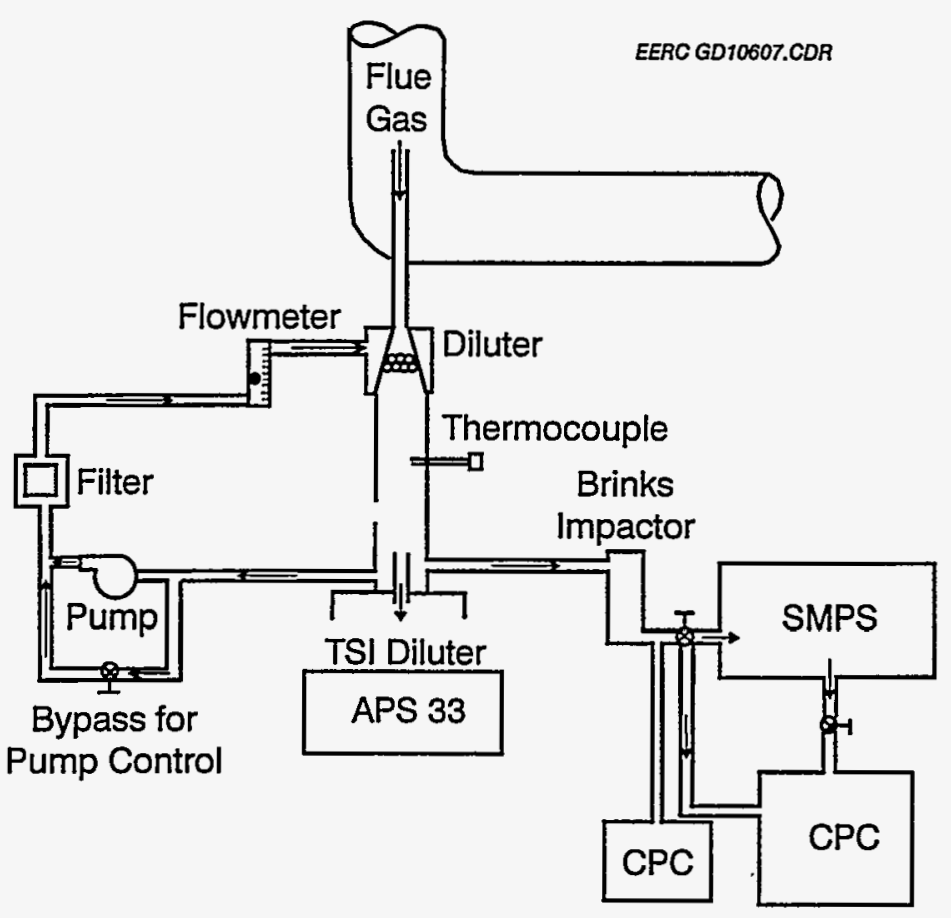

Figure 4. Schematic of particulate sampling equipment. 
piping. After the induced-draft fan was shut off, the ESP field was turned off. Ash that was not collected on the ESP plate but had fallen to the hopper was removed and weighed prior to ESP rapping. The ESP field was activated after this to remove any particulate that was reentrained when the hopper valve was opened. With the ESP current off, a sample probe was inserted into the chamber immediately below the plate. When the ESP was rapped, most of the ash dropped to the hopper, but some was redispersed and suspended in the ESP chamber. The redispersed ash was sampled. The SMPS sampled for 90 seconds immediately after the ESP plate was cleaned to determine the submicron size distribution. The APS sampled the redispersed ash for ten seconds immediately after the ESP plate cleaning, and the CPC sampled every two seconds throughout the cleaning process. A similar sampling procedure was used for the inlet. The loaded ESP plate weight, after-rap plate weight, hopper ash weight, weight of ash remaining in the inlet pipes, and weight of ash fed were recorded to determine an ash balance.

Video equipment was used to record some on-line operation of the ESP and the plate cleaning for each test condition. The video record was intended to provide qualitative information on the amount of material collected on the plate, the amount of material removed during the cleaning process, and the amount of ash reentrained during the cleaning process.

For the baghouse tests, the ash feed was turned off when the ash loading was completed. The induced-draft fan remained on for approximately three minutes to clear any ash remaining in the inlet piping. After the induced-draft fan was shut off, the top of the baghouse was removed to provide access for the video equipment. Ash that was not collected on the bag but had fallen to the hopper was removed and weighed prior to pulsing the bag. A sample probe was inserted into the baghouse chamber immediately below the bag. When the bag was pulsed, most of the ash dropped to the hopper, but some was redispersed and suspended in the pulse-jet chamber. The redispersed ash was sampled. The SMPS sampled for 90 seconds immediately after pulsing of the bag to determine the submicron size distribution. The APS sampled the redispersed ash for 10 seconds immediately after pulsing, and the CPC sampled every 2 seconds throughout the cleaning process. It was not possible to determine the bag weight before and after the bags were pulsed, but the weight of ash fed, weight of ash in the hopper before pulsing, weight of the ash removed from the bag by pulsing, and weight of the ash removed from the bag at the end of the test (by pulsing the bags 10 times at 60 -psig pulse pressure) were recorded to determine an ash balance.

Video equipment was used to record the pulsing of the bags for each test condition. The video record was intended to provide qualitative information on the amount of material collected on the bag, the amount of material removed during the cleaning process, and the amount of ash reentrained during the cleaning process.

\subsection{ACCOMPLISHMENTS/RESULTS}

From the data collected, it was possible to determine the size distribution of the injected ash and compare it to the size distribution of the original ash. Also, the size distribution of the redispersed ash was compared to the size distribution of the injected ash to determine the level of redispersion when the ESP plate was cleaned or the bag pulsed. The mass balance data give some indication of the amount of ash removed from the collection device that reached the hopper and the amount that was reentrained. 
Hopper ash samples were submitted for Coulter counter analysis, and multicyclone samples were taken at the inlet of the pulse-jet baghouse for each ash. To determine a complete size distribution of the injected ash, the Coulter counter data and the multicyclone data were combined and plotted. The Coulter counter data, based on geometric particle diameter, were converted to aerodynamic particle diameter. The Coulter counter data were then normalized to include the multicyclone data, assuming the multicyclone data provide an absolute mass distribution for the smaller particles, and the Coulter counter ignores particles smaller than a certain minimum size. Figures 5-8 present the combined Coulter counter/multicyclone inlet size distributions for each ash. The data are shown on a log-probability plot because the size distribution is expected to follow a normal distribution, which is represented by a straight line on the log-probability plot. From the figures, it can be seen that the multicyclone and Coulter counter data do not agree exactly; the injected ash did not completely redisperse to its original size distribution. However, the agreement is fairly close, indicating a reasonable level of redispersion. Figure 9 plots the multicyclone distribution for each ash. The ashes were expected to redisperse into different distributions, because they have different cohesive properties. However, little difference was displayed in the size distributions of the injected ashes, which may be a limitation of the ash injection system. Multicyclone data for the original Big Brown ash were available, and Figure 10 plots the original multicyclone size distribution and the size distribution of the injected Big Brown ash. As expected, the injected ash was not redispersed into its original size distribution, but an acceptable amount of ash was redispersed into the submicron range.

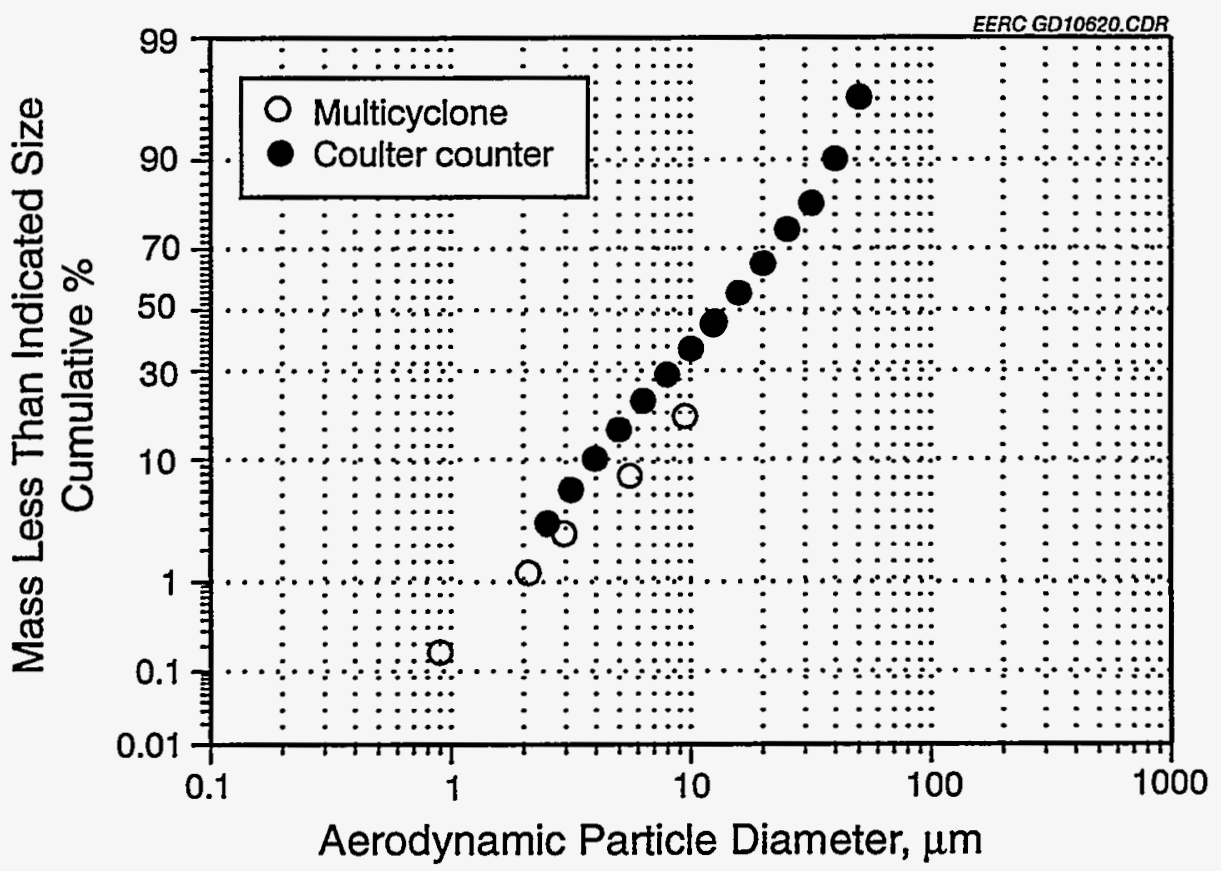

Figure 5. Combined multicyclone/Coulter counter size distribution for Absaloka ash. 


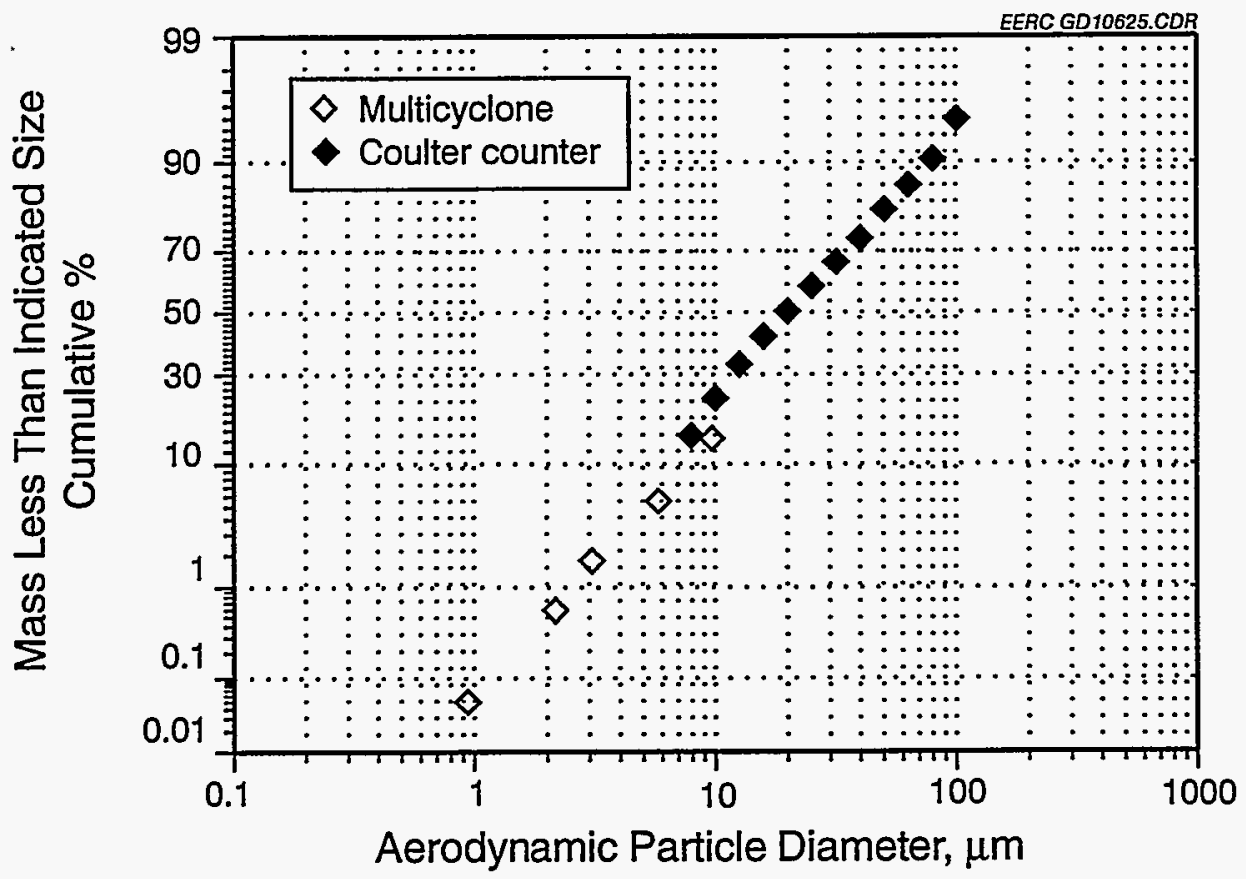

Figure 6. Combined multicyclone/Coulter counter size distribution for conditioned Big Brown ash.

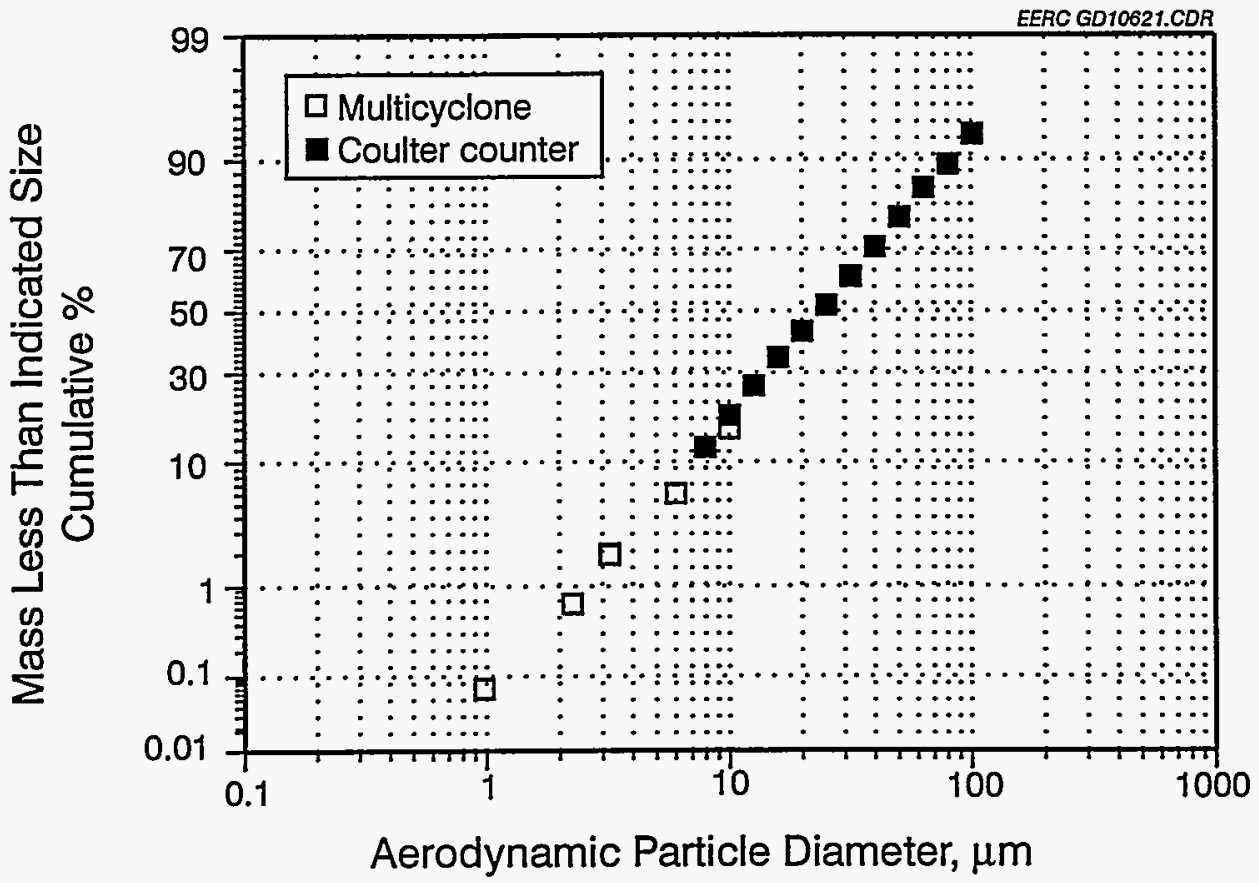

Figure 7. Combined multicyclone/Coulter counter size distribution for Big Brown ash. 


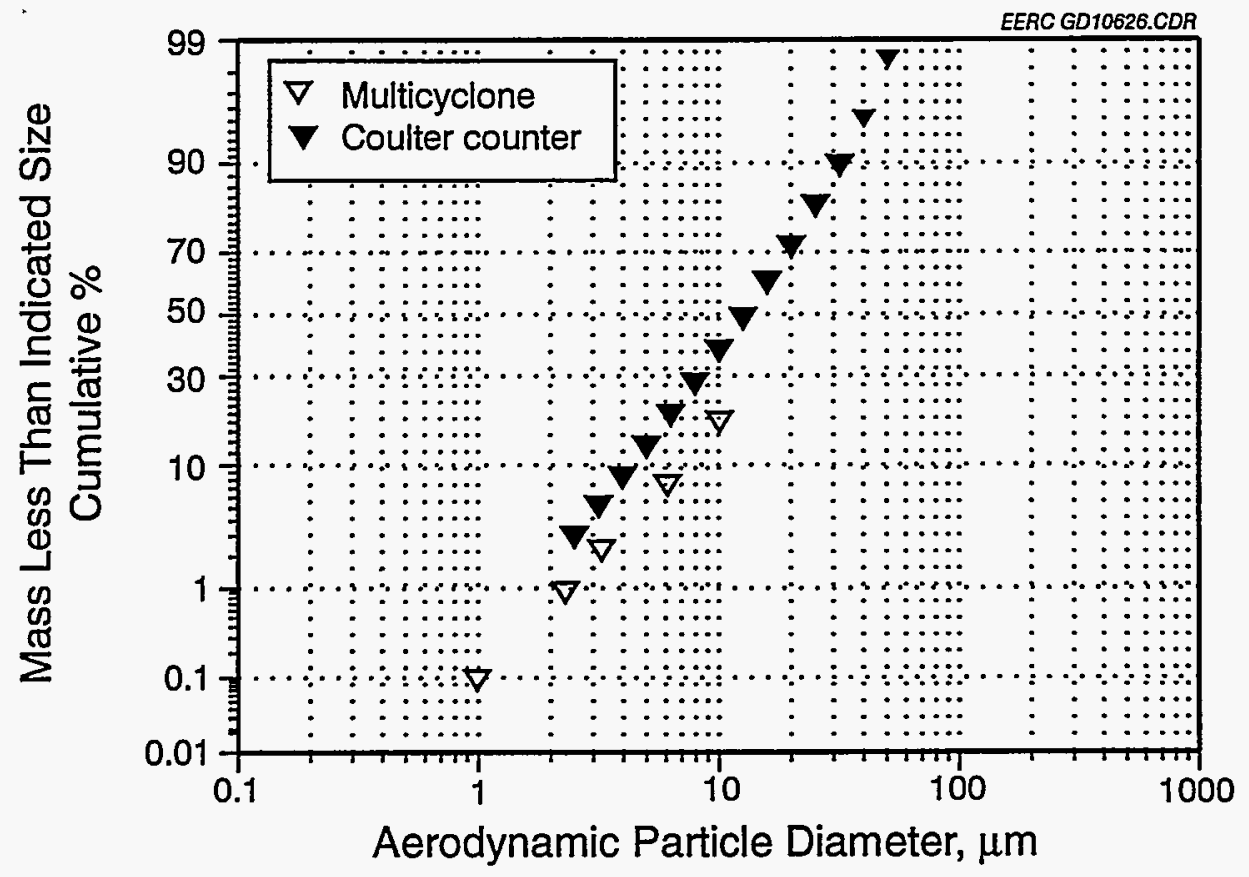

Figure 8. Combined multicyclone/Coulter counter size distribution for Blacksville ash.

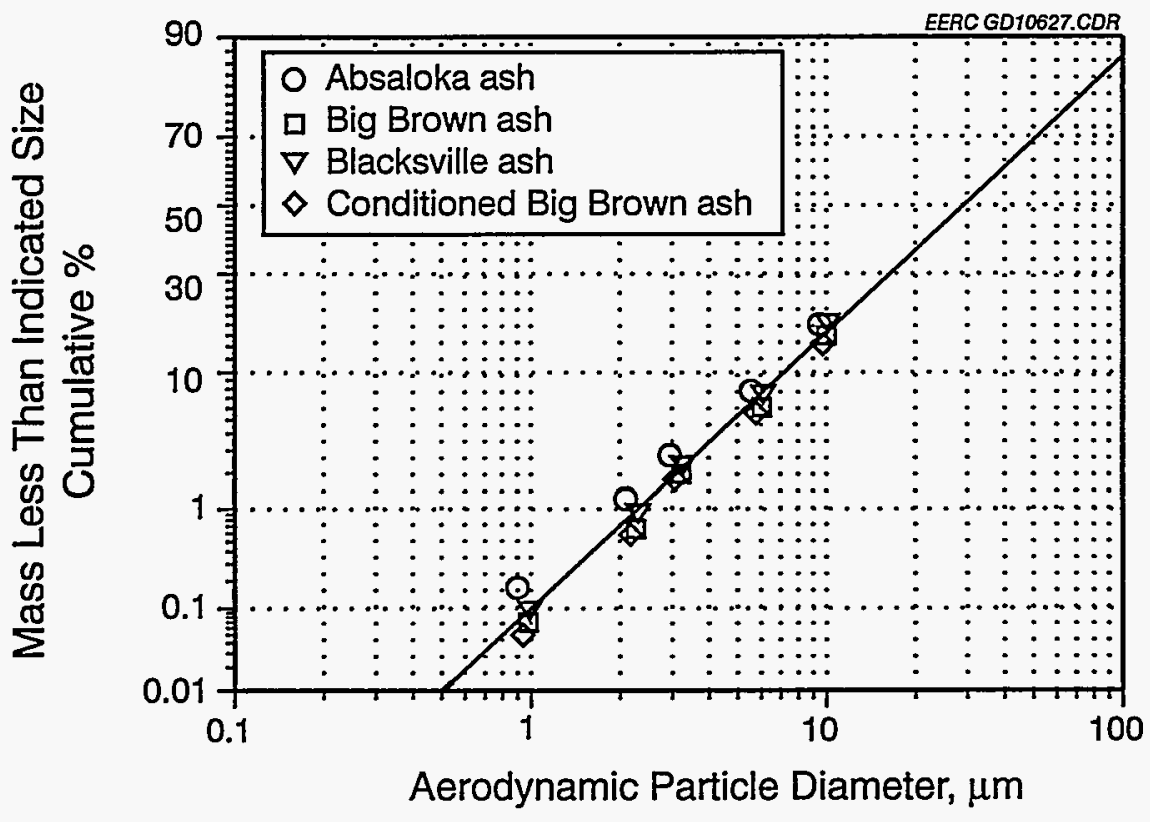

Figure 9. Multicyclone data for all ashes. 


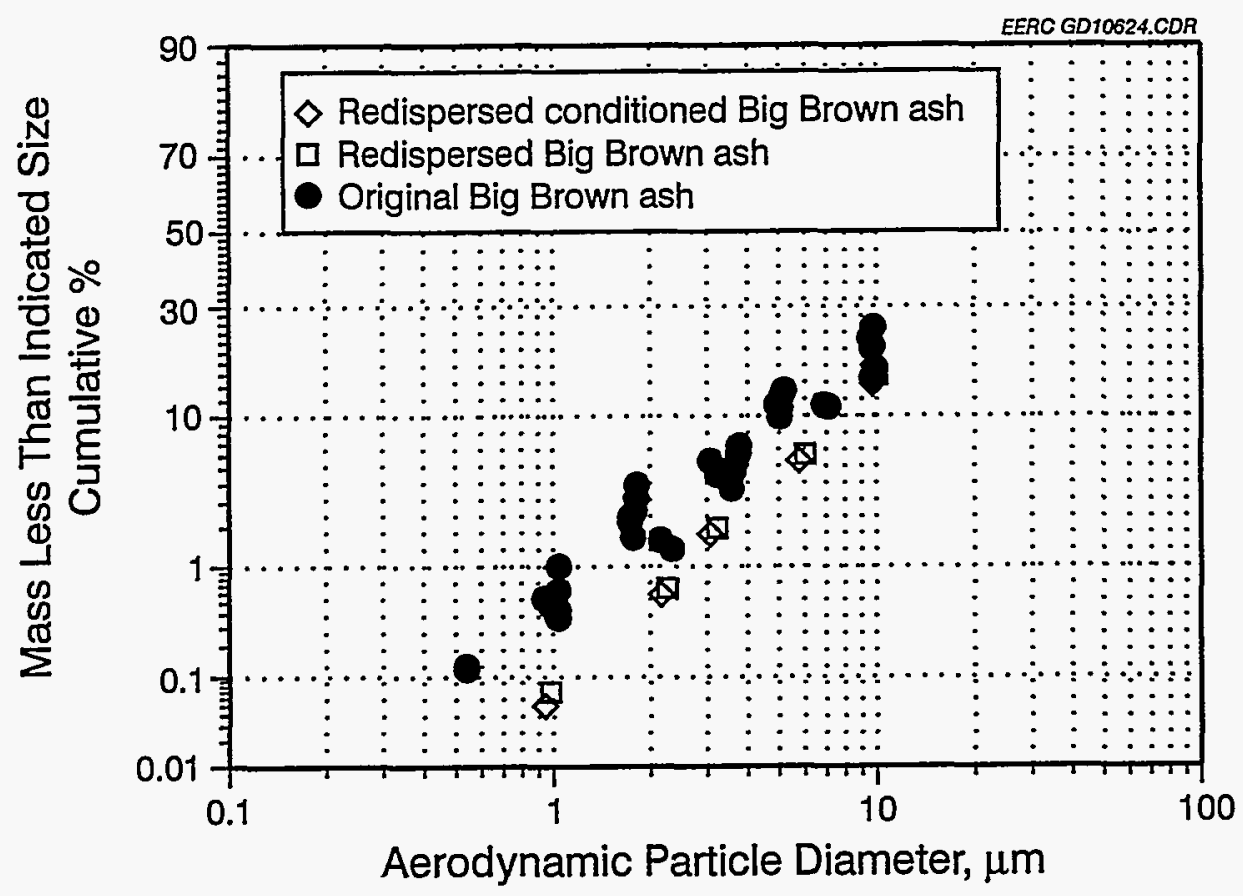

Figure 10. Multicyclone data for original and redispersed Big Brown ash.

\subsection{ESP Results}

Table 4 presents the mass balance data for each test. Because of limitations of the ESP load cell, the amount of ash suspended in the ESP chamber after cleaning was not determined. Visual inspection showed it to be a small fraction of the material removed from the plate. The percent of the collected mass removed from the plate was fairly constant from ash to ash and for each loading condition. This trend may be a function of the constant cleaning energy. With a higher cleaning energy, perhaps a larger percent of the collected ash would be removed from the plate. However, the percent of ash fed that actually was collected on the plate was different for the two loading conditions. Most of the ash was retained on the plate (90\%-97\%) when the ESP plate was loaded for $15 \mathrm{~min}$, and when the plate was loaded for $1 \mathrm{hr}$ only, $36 \%-44 \%$ of the ash fed was retained on the plate. These amounts indicated that during the 1-hr loading tests, some of the ash dropped from the ESP plate before it was cleaned, affecting the amount of ash available for reentrainment when the ESP plate was cleaned. The values for the Big Brown ash were reversed, $62 \%$ for the 15 -min loading and $85 \%$ for the 1-hr loading. This reversal may be because of the low tensile strength of the Big Brown ash. No significant correlation is apparent between the tensile strength of the ashes and the amount of material removed from the ESP plate or between the tensile strength and the amount of material collected.

To determine the extent to which the ash was redispersed when the ESP plate was cleaned, the data were plotted several ways. Figures 11 and 12 present a log-probability plot of the combined SMPS and APS size distributions for the inlet ash and the redispersed ash immediately after cleaning 


\section{TABLE 4}

ESP Mass Balance Data

\begin{tabular}{|c|c|c|c|c|c|c|c|c|c|c|}
\hline \multirow[b]{2}{*}{ Date } & \multirow[b]{2}{*}{ Coal Run No. } & \multirow[b]{2}{*}{ Ash Type } & \multirow[b]{2}{*}{$\begin{array}{c}\text { Ash } \\
\text { Collection } \\
\text { Time, min }\end{array}$} & \multirow[b]{2}{*}{ Ash Fed, lb } & \multicolumn{2}{|c|}{$\begin{array}{c}\text { Hopper Ash } \\
\text { Weight }\end{array}$} & \multicolumn{2}{|c|}{$\begin{array}{l}\text { End-of-Test } \\
\text { Ash Weight }\end{array}$} & \multirow[b]{2}{*}{$\begin{array}{l}\% \text { Ash Fed } \\
\text { Collected }\end{array}$} & \multirow[b]{2}{*}{$\begin{array}{l}\% \text { Collected } \\
\text { Ash Removed }\end{array}$} \\
\hline & & & & & $\begin{array}{l}\text { Before } \\
\text { Rap, 1b }\end{array}$ & $\begin{array}{c}\text { After } \\
\text { Rap, lb }\end{array}$ & $\begin{array}{c}\text { Inlet } \\
\text { Piping, lb }\end{array}$ & $\begin{array}{c}\mathrm{ESP}, \\
\mathrm{lb}\end{array}$ & & \\
\hline $04 / 27 / 94$ & $\mathrm{AB}-445$ & Absaloka & 15 & 1.7 & 0.10 & 1.20 & 0.07 & 0.38 & 96.9 & 75.9 \\
\hline $04 / 27 / 94$ & BB-386 & Big Brown & 15 & 1.75 & 0.08 & 0.81 & 0.07 & 0.23 & 61.9 & 77.9 \\
\hline $04 / 28 / 94$ & BB-386 & Big Brown & 60 & 6.6 & 0.92 & 4.46 & 0.07 & 1.10 & 85.1 & 80.2 \\
\hline $04 / 28 / 94$ & $\mathrm{AB}-445$ & Absaloka & 60 & 6.25 & 3.66 & 1.86 & 0.02 & 0.73 & 41.6 & 71.8 \\
\hline $04 / 29 / 94$ & BB-384 & Big Brown & 60 & 7.45 & 4.16 & 2.06 & 0.02 & 0.60 & 35.8 & 77.4 \\
\hline $04 / 29 / 94$ & BB-384 & Big Brown & 15 & 1.8 & 0.28 & 1.15 & 0.13 & 0.36 & 90.4 & 76.2 \\
\hline $06 / 02 / 94$ & BV -473 & Blacksville & 60 & 6.6 & 2.48 & 2.33 & 0.36 & 0.41 & 43.9 & 85.0 \\
\hline $06 / 13 / 94$ & BV -473 & Blacksville & 15 & 1.35 & 0.00 & 0.82 & 0.15 & 0.32 & 95.0 & 71.9 \\
\hline
\end{tabular}




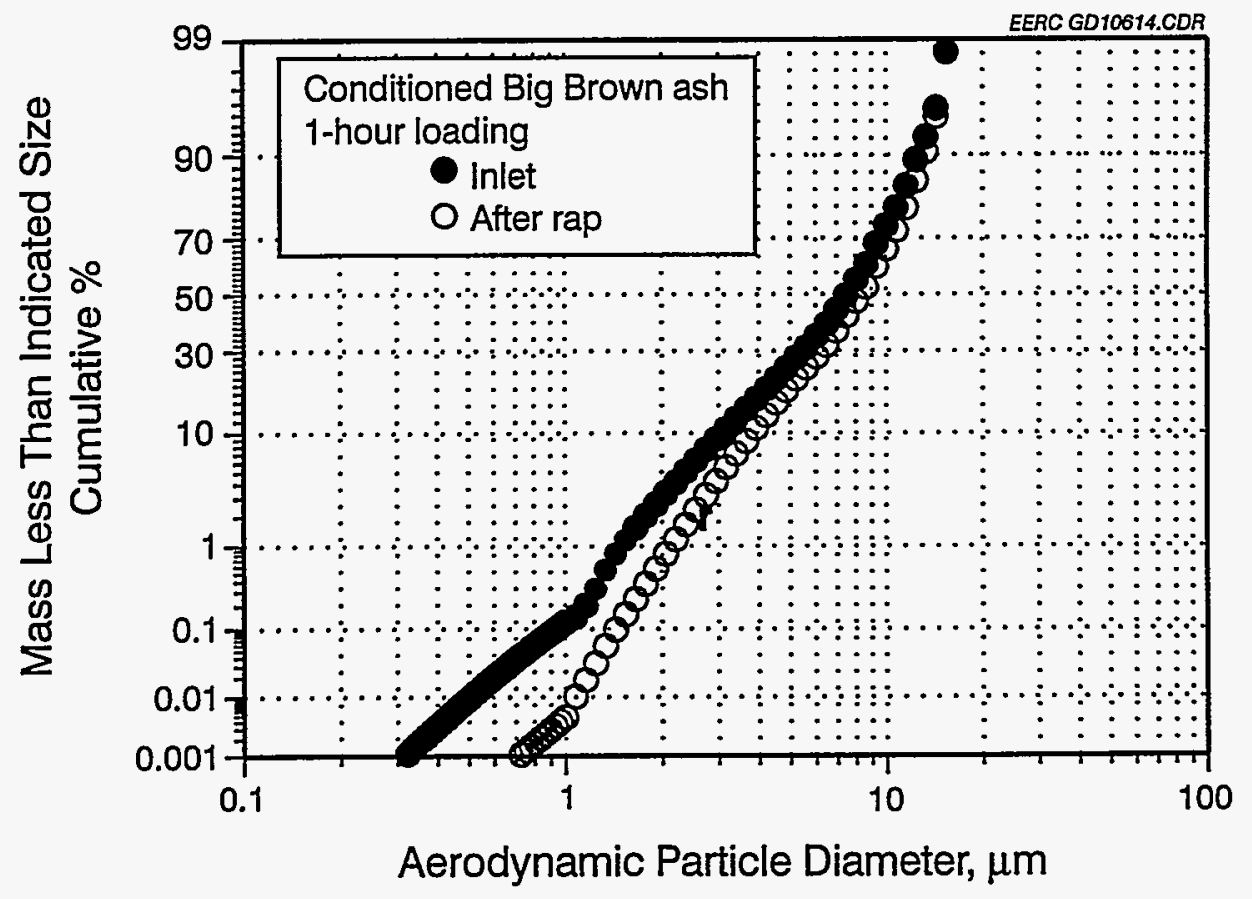

Figure 11. Combined inlet and after-ESP-cleaning SMPS/APS size distributions for conditioned Big Brown ash, 1-hr loading.

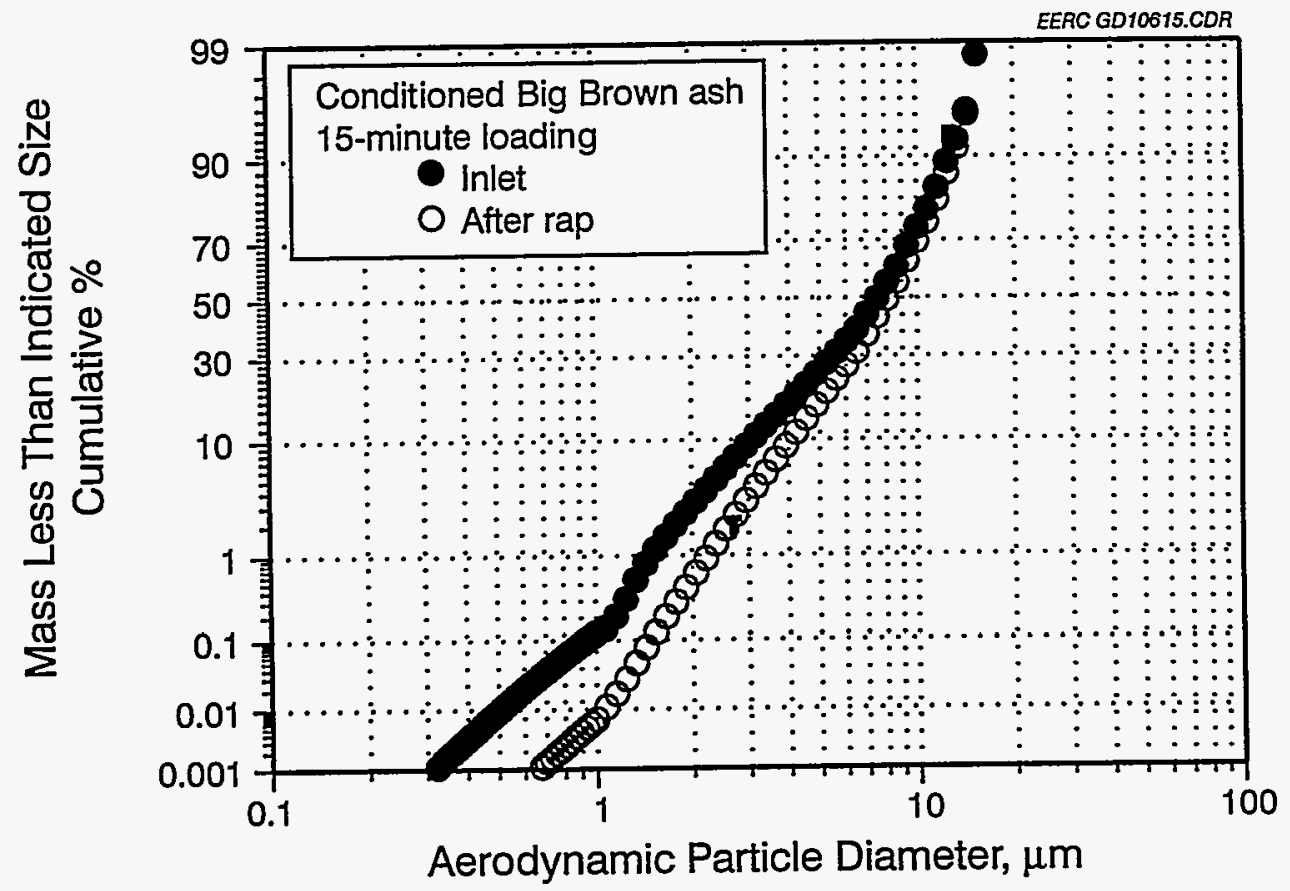

Figure 12. Combined inlet and after-ESP-cleaning SMPS/APS size distributions for conditioned Big Brown ash, 15-min loading. 
of the ESP plate. The plots presenting the data for the runs using the conditioned Big Brown ash are typical of the results with the other ashes. The figures include data from the SMPS and APS, but do not represent the entire size distribution. Particles less than approximately $0.03 \mu \mathrm{m}$ and larger than approximately $15 \mu \mathrm{m}$ in diameter are not included. However, for the purpose of comparison, the figures are useful. The size distribution for each ash is similar, and the ash type had little apparent effect on the size distribution of the injected ashes. These results were somewhat expected, since the injected ashes had similar inlet size distributions, based on the multicyclone data. The plots do, however, indicate that the ashes were redispersed to a larger size distribution when the ESP plate was rapped, most likely because the agglomerations of the smaller particles during collection did not redisperse when the plate was rapped. From these plots, no correlation with the tensile strength data is evident.

The data from the SMPS, APS, and CPC were also used to compare the particle concentrations of the inlet ash and the ash reentrained when the ESP plate was cleaned. For each test, the mass median diameter, total mass, and respirable mass as determined by APS for each inlet sample and for each sample collected after cleaning of the ESP plate are presented in Table 5. The average inlet concentration and the peak concentration after cleaning the ESP plate, based on the CPC data, are also presented. These values do not represent the entire size distribution, but they are representative and can be used for comparison. The mass median diameter data indicate the ash (after 1-hr loading) is redispersed to a larger size distribution than the inlet particle distribution. The mass median data for the 15-min loading of the ESP plate indicates the ash is redispersed approximately into its original (inlet) size distribution. The total and respirable mass data show the effect of ash layer thickness on redispersion. As expected, more mass is redispersed from the thicker ash layer (1-hr loading). The exception was the Big Brown ash conditioned with $\mathrm{NH}_{3}$ and $\mathrm{SO}_{3}$, which showed no effect. The inlet CPC data display an inverse relationship to the tensile strength data. Based on the tensile strength data, the Blacksville ash was expected to be the most difficult to redisperse in the submicron region and the baseline Big Brown ash to be the easiest. However, the CPC data indicate the inlet concentration of submicron particles for the Blacksville ash was the highest and the baseline Big Brown the lowest. This may be because the original inlet Blacksville had much more submicron particles present. The submicron concentrations after rapping of the ESP do not follow the same pattern; therefore, the inlet concentrations may be artifacts of the ash injection system.

Figures $13-20$ show plots of the ratio of after-ESP-plate-cleaning particle concentration to inlet particle concentration at each test condition, based on the combined SMPS/APS data. Again, the plots do not represent the entire size distribution but are useful for comparison purposes. For some of the plots, a slight discontinuity exists between the SMPS and the APS data. This can be attributed to the difference in the measured particle diameters. The SMPS measures an electric mobility diameter, which is more a geometric than an aerodynamic diameter. Therefore, a difference occurs in conversion to an aerodynamic diameter. Also, the area of data overlap is at the extreme ranges of both instruments. For all but the 1-hr loading of the Blacksville ash, the concentrations of the redispersed submicron particles were lower than the inlet concentrations, while the concentrations of particles larger than $1 \mu \mathrm{m}$ were greater than those of the inlet. These data indicate that upon ESP plate cleaning the ash was redispersed as larger particles, which are easier to recollect and less likely to be carried out the stack. Again, the effect of the ash layer thickness is evident for all but the conditioned Big Brown ash. Also evident from the plots is that the overall concentration of particles increases with increasing ash layer thickness. The effect of the ash layer thickness is most 
TABLE 5

APS and CPC Statistical Data

\begin{tabular}{|c|c|c|c|c|c|c|c|c|c|c|c|c|}
\hline \multirow[b]{2}{*}{ Ash } & \multicolumn{4}{|c|}{ Inlet Average } & \multicolumn{4}{|c|}{ 1-Hour Loading } & \multicolumn{4}{|c|}{ 15-Minute Loading } \\
\hline & $\begin{array}{c}\text { Mass } \\
\text { Median } \\
\text { Diameter, } \\
\mu \mathrm{m}\end{array}$ & $\begin{array}{l}\text { Total } \\
\text { Mass, } \\
\mathrm{mg} / \mathrm{m}^{3} \\
\end{array}$ & $\begin{array}{c}\text { Respirable } \\
\text { Mass, } \\
\mathrm{mg} / \mathrm{m}^{3} \\
\end{array}$ & $\begin{array}{c}\mathrm{CPC} \\
\begin{array}{c}\text { Concentration, } \\
\text { part. } / \mathrm{cm}^{3}\end{array} \\
\end{array}$ & $\begin{array}{c}\text { Mass } \\
\text { Median } \\
\text { Diameter, } \\
\mu \mathrm{m} \\
\end{array}$ & $\begin{array}{l}\text { Total } \\
\text { Mass, } \\
\mathrm{mg} / \mathrm{m}^{3}\end{array}$ & $\begin{array}{c}\text { Respirable } \\
\text { Mass, } \\
\mathrm{mg} / \mathrm{m}^{3} \\
\end{array}$ & $\begin{array}{c}\mathrm{CPC} \\
\text { Concentration, } \\
\text { part. } / \mathrm{cm}^{3}\end{array}$ & $\begin{array}{c}\text { Mass } \\
\text { Median } \\
\text { Diameter, } \\
\mu \mathrm{m} \\
\end{array}$ & $\begin{array}{l}\text { Total } \\
\text { Mass, } \\
\mathrm{mg} / \mathrm{m}^{3} \\
\end{array}$ & $\begin{array}{c}\text { Respirable } \\
\text { Mass, } \\
\mathrm{mg} / \mathrm{m}^{3} \\
\end{array}$ & $\begin{array}{c}\mathrm{CPC} \\
\begin{array}{c}\text { Concentration, } \\
\text { part. } / \mathrm{cm}^{3}\end{array} \\
\end{array}$ \\
\hline Absaloka & 5.00 & 7727 & 1363 & 364967 & 9.28 & 121000 & 14140 & 271791 & 7.16 & 38710 & - & 90194 \\
\hline Big Brown & 7.60 & 5922 & 1089 & 497698 & 8.36 & 80200 & 10920 & 90345 & 8.11 & 83700 & 10780 & 95871 \\
\hline Big Brown & 7.81 & 4169 & 690 & 192546 & 8.84 & 107000 & 13500 & 194304 & 7.22 & 24600 & 4414 & 98481 \\
\hline Blacksville & 6.62 & 5714 & 1407 & 523698 & 6.88 & 39100 & 7467 & 88071 & 8.05 & 5480 & 561 & 35280 \\
\hline
\end{tabular}




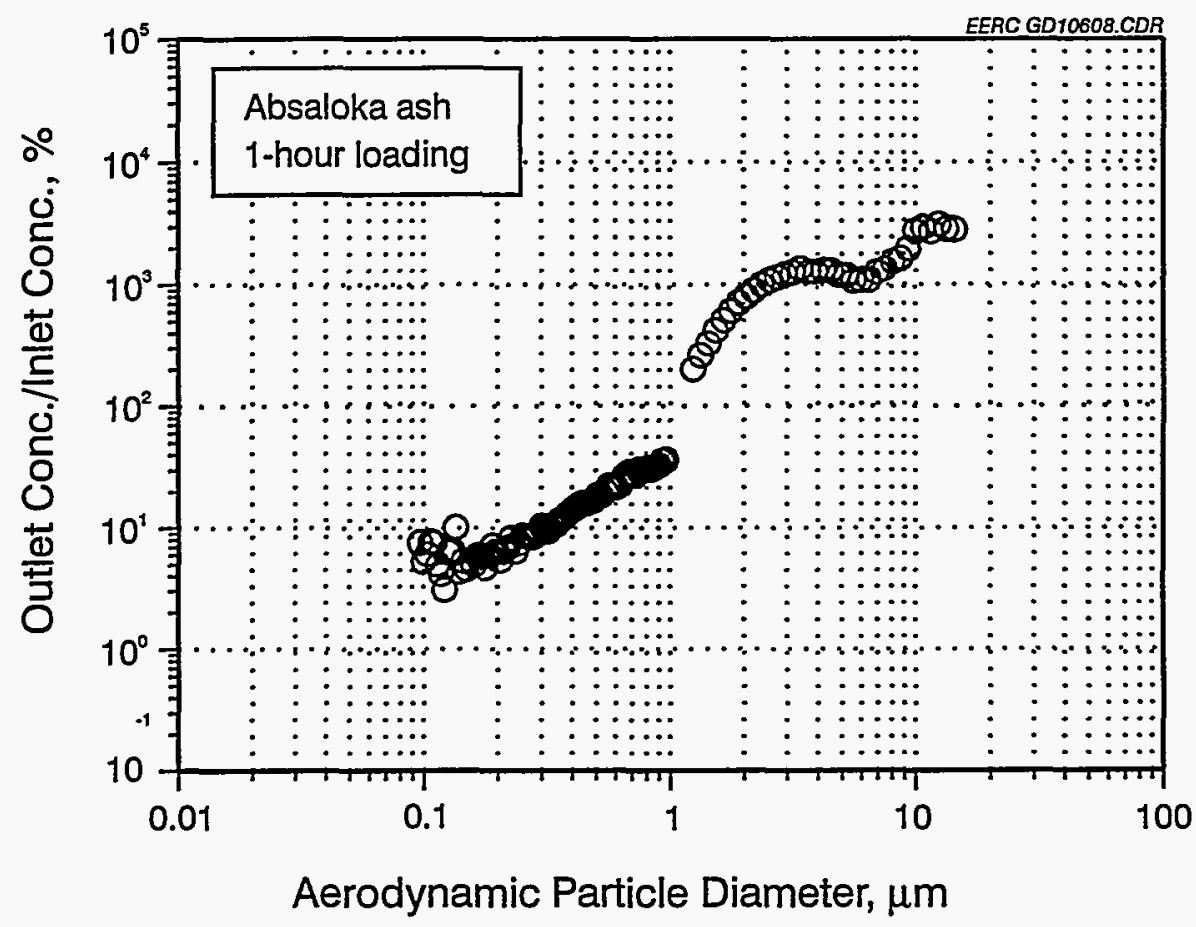

Figure 13. Ratio of after-ESP-plate-cleaning concentration to inlet concentration, based on the combined SMPS/APS data, 1-hr loading, Absaloka ash.

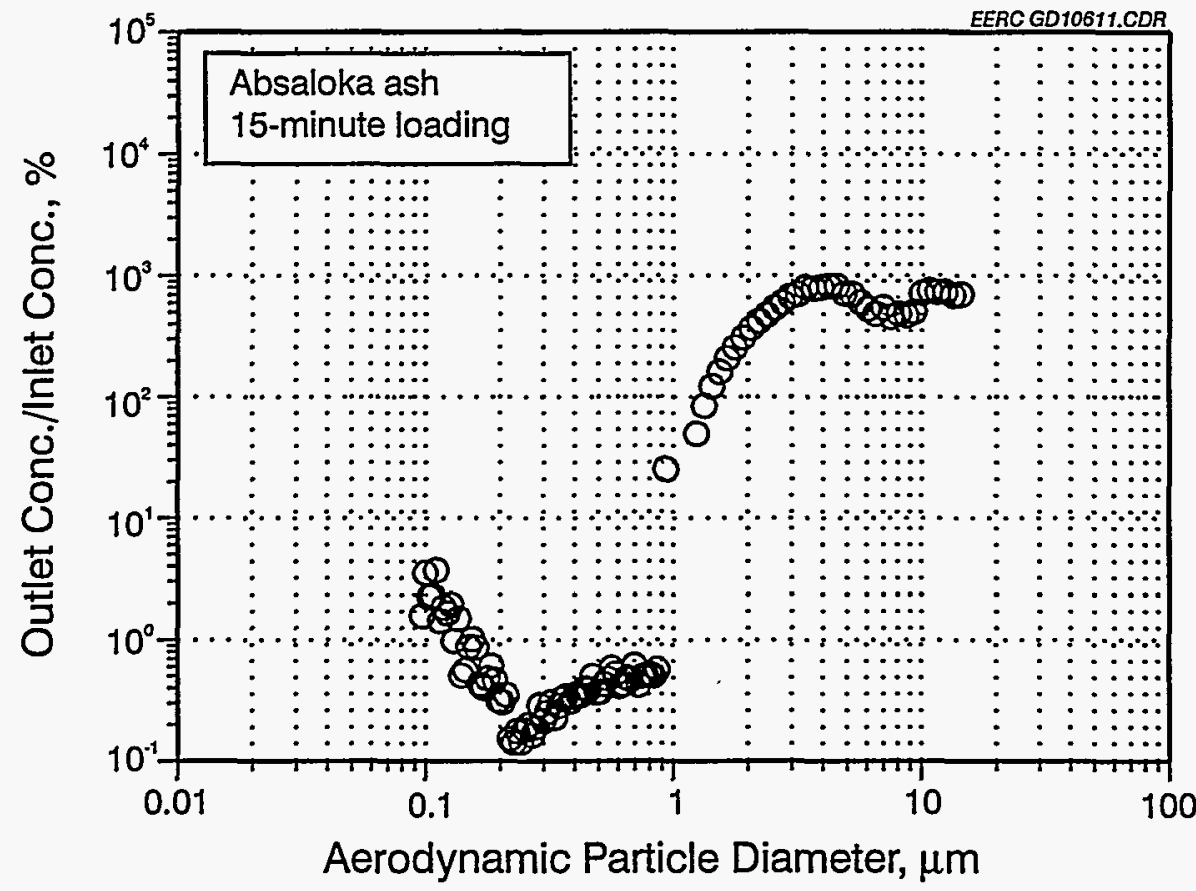

Figure 14. Ratio of after-ESP-plate-cleaning concentration to inlet concentration, based on the combined SMPS/APS data, 15-min loading, Absaloka ash. 


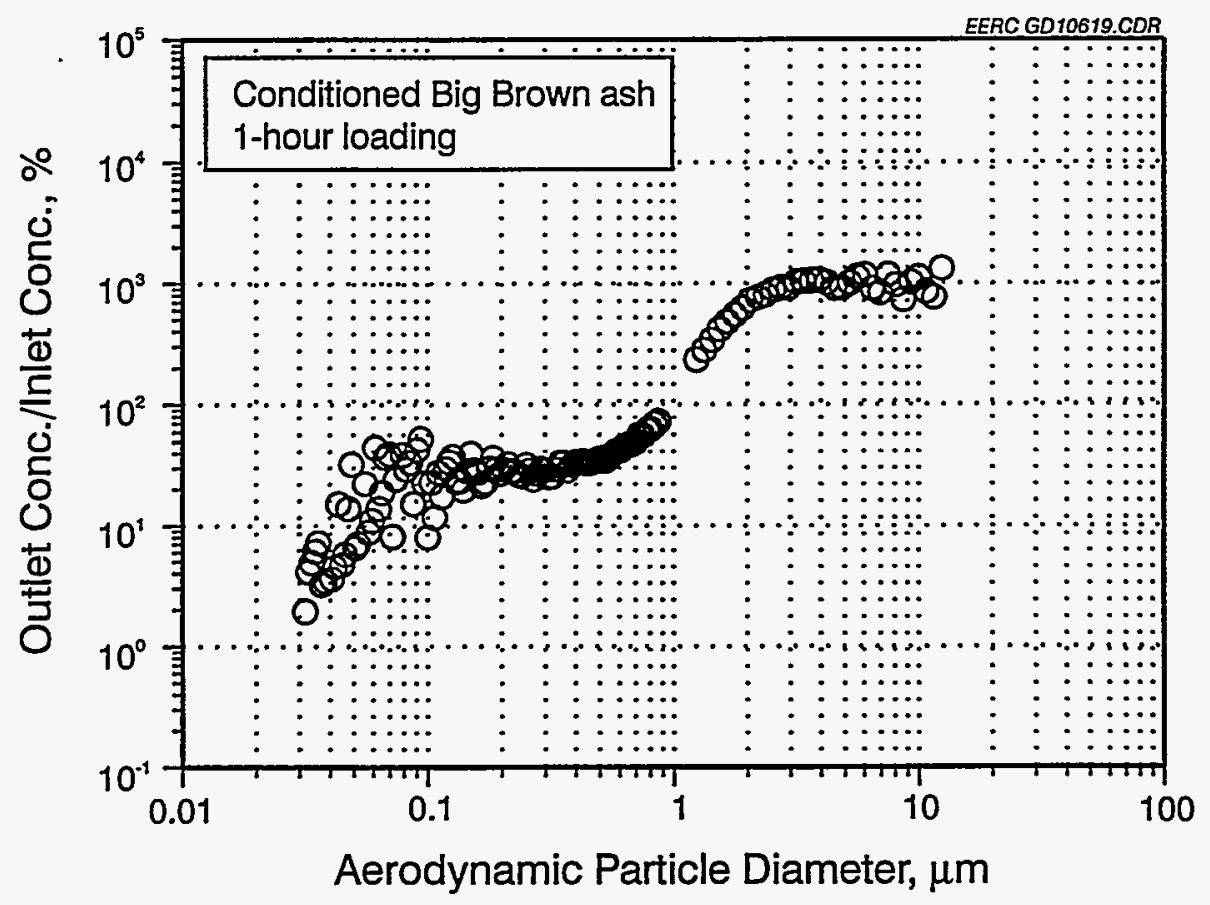

Figure 15. Ratio of after-ESP-plate-cleaning concentration to inlet concentration, based on the combined SMPS/APS data, 1-hr loading, conditioned Big Brown ash.

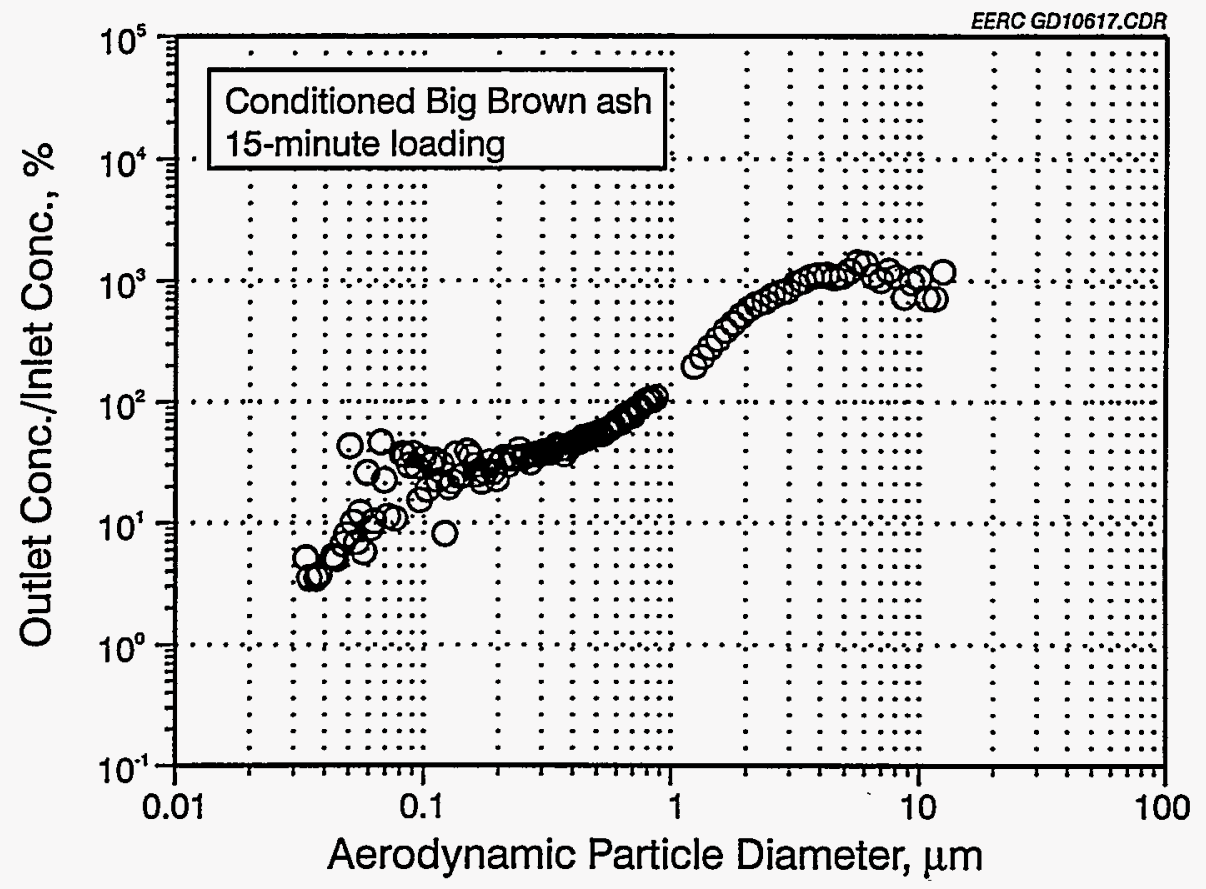

Figure 16. Ratio of after-ESP-plate-cleaning concentration to inlet concentration, based on the combined SMPS/APS data, 15-min loading, conditioned Big Brown ash. 


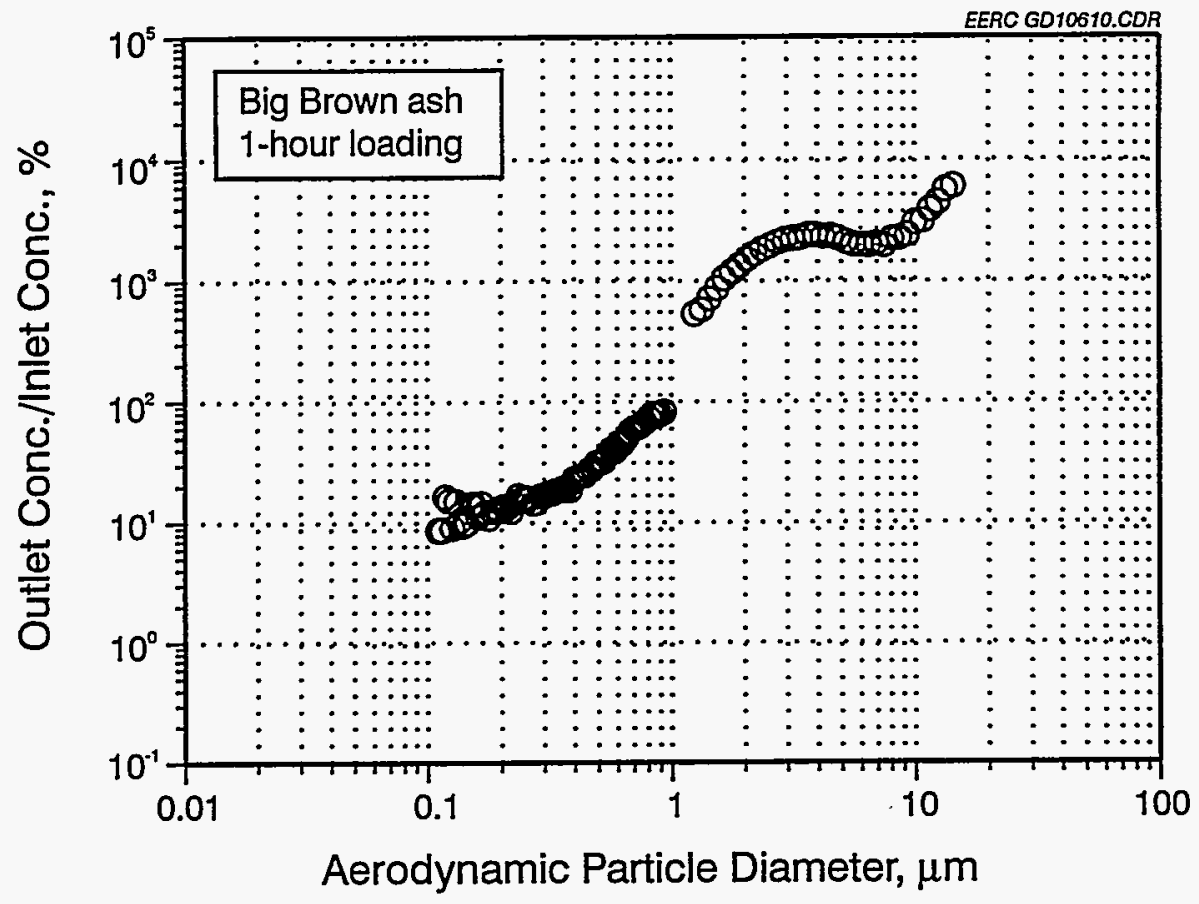

Figure 17. Ratio of after-ESP-plate-cleaning concentration to inlet concentration, based on the combined SMPS/APS data, 1-hr loading, Big Brown ash.

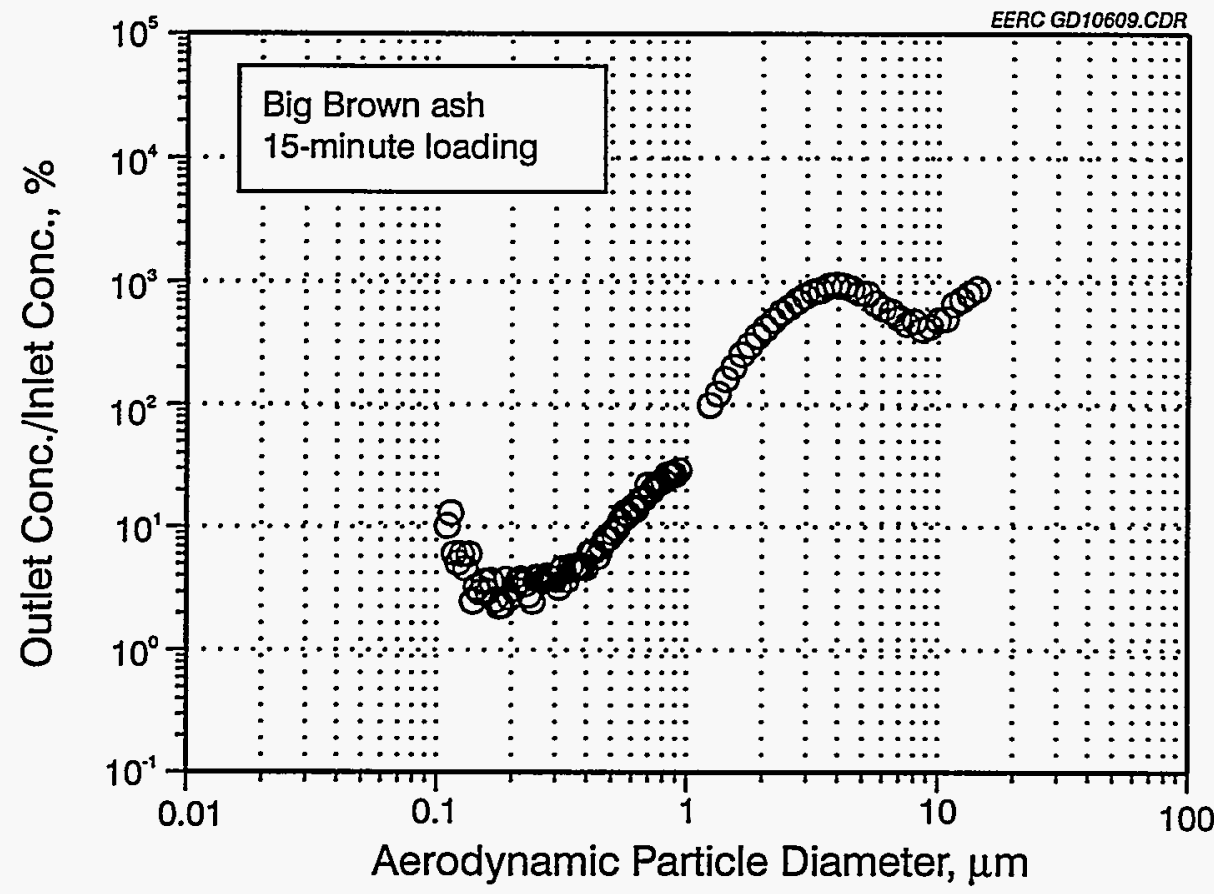

Figure 18. Ratio of after-ESP-plate-cleaning concentration to inlet concentration, based on the combined SMPS/APS data, 15-min loading, Big Brown ash. 


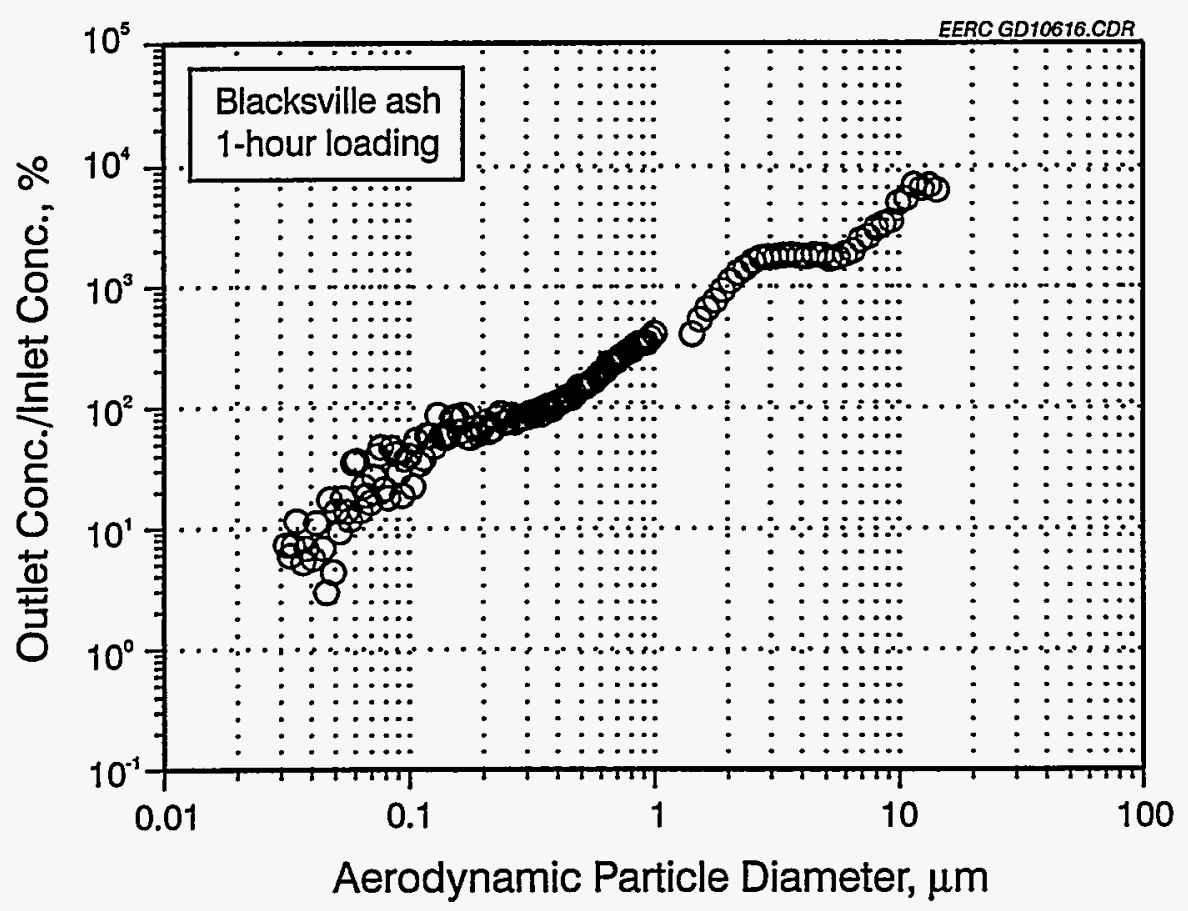

Figure 19. Ratio of after-ESP-plate-cleaning concentration to inlet concentration, based on the combined SMPS/APS data, 1-hr loading, Blacksville ash.

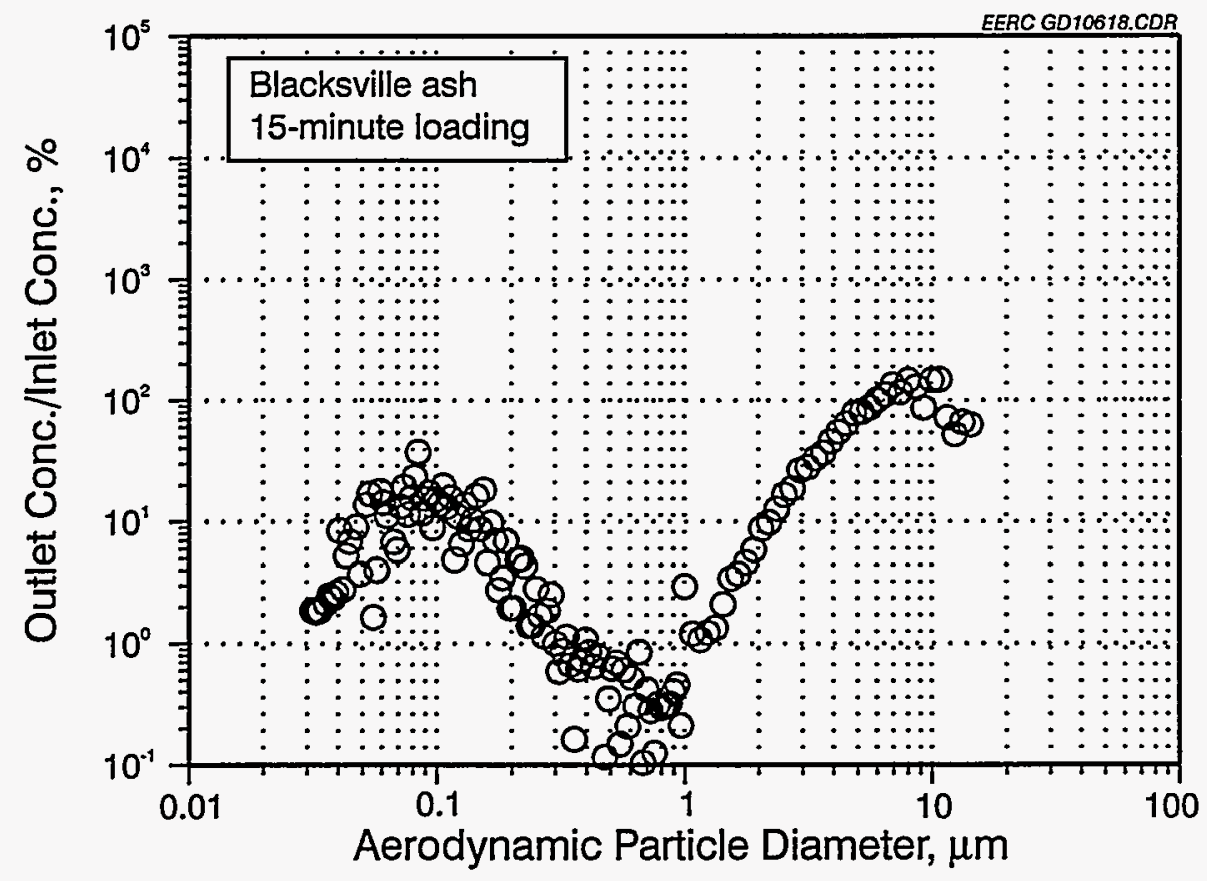

Figure 20. Ratio of after-ESP-plate-cleaning concentration to inlet concentration, based on the combined SMPS/APS data, 15-min loading, Blacksville ash. 
pronounced for the Absaloka and Blacksville ashes. Figure 21 plots the ratio of after-ESP-platecleaning particle concentration to inlet particle concentration, as a function of time, for the 1-hr loading of the Absaloka ash. Only APS data were used since the APS sampled approximately once every 10 seconds, and the SMPS sampled once every 90 seconds. The main effect observed was the dilution of the ash cloud in the ESP chamber with time. To a smaller extent, the settling effect of larger particles was also observed. The settling velocity of a $10-\mu \mathrm{m}$ particle (unit density sphere) is approximately $0.3 \mathrm{~cm} / \mathrm{sec}$, and the settling velocity of a $1-\mu \mathrm{m}$ particle is approximately 0.0035 $\mathrm{cm} / \mathrm{sec}$. The difference in settling velocities is almost two orders of magnitude. Therefore, for every unit change in the concentration of the $1-\mu \mathrm{m}$ particles, the concentration of the $10-\mu \mathrm{m}$ particles will change by two orders of magnitude. With increasing time, the shape of the curve would change, with the ratio of the larger particles dropping off quickly and the concentration ratio of the smaller particles remaining high. Instead, the plot shows an almost equal drop in the concentration ratios for all particles. This phenomenon is characteristic of a dust cloud becoming more dilute with time.

Video equipment was used to record the cleaning of the ESP plate. The video shows that ash was removed only from roughly the bottom third of the ESP plate. However, most of the ash that was removed fell to the hopper as large agglomerates. The video also showed the ash cloud disperse and become more dilute shortly after the ESP plate was cleaned. The particle concentration data are consistent with these observations.

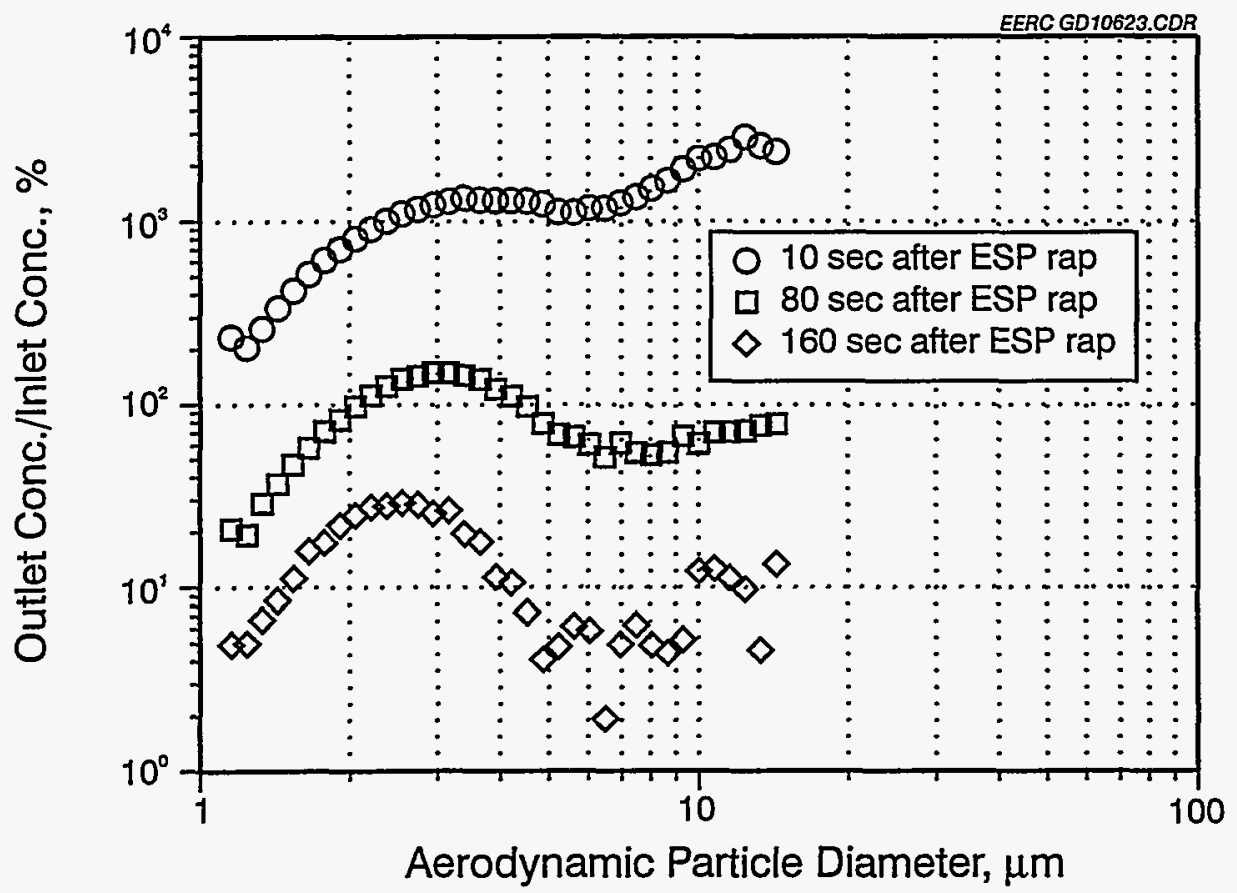

Figure 21. Ratio of after-ESP-plate-cleaning concentration to inlet concentration as a function of time, based on APS data, 1-hr loading, Absaloka ash. 


\subsection{Baghouse Results}

Table 6 presents the mass balance data for each test. The percent of the collected mass removed from the bag varied both from ash to ash and with cleaning energy. Apparently, the Blacksville ash was the easiest to remove from the bags: $93.5 \%$ was removed at 20 psig pulse pressure, and $97.3 \%$ was removed at 60 psig pulse pressure. Little difference was evident between the other ashes. For the other ashes evaluated at 60 psig pulse pressure, the percent removed ranged from $88.1 \%$ to $92.0 \%$, while 20 psig pulse pressure removed $84.0 \%-89.3 \%$. The difference between pulsing pressures was expected to be more pronounced, with more ash removed with higher pulse pressure. The mass balance for each run does not include any ash in the inlet piping or ash remaining on the bag after being pulsed 10 times (at 60 psig pulse pressure) after each test. Apparently a data error occurred during the run with the conditioned Big Brown lignite ash. The measured amount of ash fed is low by roughly a factor of 3 from the expected amount. Also, the amount of ash collected in the hopper indicates more ash was fed than measured.

The percent of ash removed from the bag does correlate with the tensile strength data. It is most pronounced when the pulse pressure was 20 psig. Again, the correlation is the opposite of that expected. The ash with the highest tensile strength was the easiest to remove from the bag, and the ash with the lowest tensile strength was the most difficult. These results may be owing to the higher-tensile-strength ash forming a more porous dust cake on the bag, while the lower-strength ash penetrated the bag, and the ash was trapped in the fabric when the bag was pulsed. The run data indicate the time for the pressure drop across the bags to reach 7 in. W.C. for the Blacksville ash was twice as long as for the other ashes. This time lag indicates the development of a more porous dust cake.

To determine the extent to which the ash redispersed when the bag was pulsed, the data from the SMPS, APS, and CPC were used to compare the particle concentrations of the inlet ash and the ash reentrained when the bag was pulsed. The mass median diameter, total mass, and respirable mass, as determined by the APS, for each inlet sample and after pulsing of the bag for each test are presented in Table 7. The average inlet CPC concentration and the peak concentration after pulsing of the bag are also presented. These values do not represent the entire size distribution, but they are representative and can be used for comparison. The mass median diameter data indicate that the Absaloka and baseline and conditioned Big Brown ashes were redispersed to smaller size distributions than those at the inlet, and the Blacksville ash was redispersed to a larger size distribution than that of the inlet particle-size distribution.

Figures 22-31 plot the ratio of after-bag-cleaning particle concentration to inlet particle concentration for each test condition versus aerodynamic particle diameter, based on the combined SMPS/APS data. Again, this does not represent the entire size distribution, but it is useful for comparison purposes. For the baghouse tests, no effect is evident owing to ash type or pulse pressure. The lack of effect from increased pulse pressure may result from the fact that 20 psig was the upper limit of effective cleaning pressure. Figures $22-31$ also show a slight decrease in the size distribution with decreasing ash layer thickness. This again may be masked by the pulse pressure level. The plots indicate that for all tests, the ash was not redispersed to its original size distribution. Particles larger than roughly $3 \mu \mathrm{m}$ were redispersed to their original size distribution, but smaller particles agglomerated to form larger particles. Regardless of the mechanism, the plots indicate fewer submicron particles redispersed after pulsing. 


\section{TABLE 6}

Baghouse Mass Balance Data

\begin{tabular}{|c|c|c|c|c|c|c|c|c|c|c|c|c|c|c|c|c|c|}
\hline \multirow[b]{2}{*}{ Date } & \multirow[b]{2}{*}{$\begin{array}{l}\text { Coal } \\
\text { Run } \\
\text { No. }\end{array}$} & \multirow[b]{2}{*}{ Ash Type } & \multirow[b]{2}{*}{$\begin{array}{c}\text { Test } \\
\text { Duration, } \\
\text { min }\end{array}$} & \multirow[b]{2}{*}{$\begin{array}{c}\text { Gas } \\
\text { Flow, } \\
\text { scfm }\end{array}$} & \multirow[b]{2}{*}{$\begin{array}{c}\text { Relative } \\
\text { Humidity, } \\
\% \\
\end{array}$} & \multirow[b]{2}{*}{$\begin{array}{c}\text { Pulse } \\
\text { Pressure, } \\
\text { psig }\end{array}$} & \multirow{2}{*}{$\begin{array}{c} \\
\text { Nominal } \\
\text { Pressure } \\
\text { Drop, } \\
\text { in. } \mathrm{H}, \mathrm{O} \\
\end{array}$} & \multirow[b]{2}{*}{$\begin{array}{c}\text { Grain } \\
\text { Loading, } \\
\text { gr/sof }\end{array}$} & \multirow[b]{2}{*}{$\begin{array}{l}\text { Ash } \\
\text { Fed, } \\
\text { lb }\end{array}$} & \multicolumn{2}{|c|}{$\begin{array}{l}\text { Hopper Ash } \\
\text { Weight }\end{array}$} & \multicolumn{2}{|c|}{$\begin{array}{c}\text { Filter Bag } \\
\text { Weight }\end{array}$} & \multirow[b]{2}{*}{$\begin{array}{c}\text { Residual } \\
\text { Dust Cake } \\
\text { Weight, } \\
\text { lb }\end{array}$} & \multirow[b]{2}{*}{$\begin{array}{c}\text { End of } \\
\text { Test Ash } \\
\text { Collected, } \\
\text { lb }\end{array}$} & \multirow[b]{2}{*}{$\begin{array}{c}\% \text { Ash } \\
\text { Collected } \\
\text { Removed } \\
\text { after } 1 \text { Pulse }\end{array}$} & \multirow[b]{2}{*}{$\begin{array}{c}\text { Mass } \\
\text { Balance, } \\
\% \\
\%\end{array}$} \\
\hline & & & & & & & & & & $\begin{array}{c}\text { Before } \\
\text { Pulse, } \\
\text { lb }\end{array}$ & $\begin{array}{c}\text { After } \\
1 \text { Pulse, } \\
\text { lb }\end{array}$ & $\begin{array}{c}\text { Initial, } \\
\text { lb }\end{array}$ & $\begin{array}{c}\text { Final, } \\
\text { lb }\end{array}$ & & & & \\
\hline $6 / 21 / 94$ & $\mathrm{AB}-445$ & Absaloka & 26.0 & 129.7 & 35 & 20 & 7.0 & 5.2 & 2.50 & 0.49 & 1.41 & 2.7 & 3.02 & 0.36 & 0.23 & 86.0 & 99.6 \\
\hline $6 / 22 / 94$ & $\mathrm{AB}-445$ & Absaloka & 24.0 & 130.3 & 59 & 60 & 7.0 & 5.1 & 2.30 & 0.50 & 1.62 & & & & 0.14 & 92.0 & 98.3 \\
\hline $6 / 22 / 94$ & AB-445 & Absaloka & 7.0 & 129.9 & 54 & 20 & 2.0 & 7.7 & 1.00 & 0.18 & 0.47 & & & & 0.10 & 82.5 & 75.0 \\
\hline $6 / 22 / 94$ & AB-445 & Absaloka & 7.0 & 129.8 & 55 & 60 & 2.0 & 4.6 & 0.60 & 0.16 & 0.45 & & & & 0.10 & 81.8 & 118.3 \\
\hline $6 / 23 / 94$ & BB-386 & $\begin{array}{l}\text { Big Brown } \\
\text { (baseline) }\end{array}$ & 31.0 & 129.7 & 55 & 60 & 7.0 & 6.8 & 3.90 & 0.71 & 1.60 & 2.7 & 3.07 & 0.42 & 0.17 & 90.4 & 74.4 \\
\hline $6 / 23 / 94$ & BB-386 & $\begin{array}{l}\text { Big Brown } \\
\text { (baseline) }\end{array}$ & 22.0 & 129.8 & 42 & 20 & 7.0 & 6.0 & 2.45 & 0.80 & 1.21 & & & & 0.23 & 84.0 & 91.4 \\
\hline $6 / 23 / 94$ & BB-386 & $\begin{array}{l}\text { Big Brown } \\
\text { (baseline) }\end{array}$ & 18.0 & 129.8 & 36 & 60 & 7.0 & 7.0 & 2.35 & 0.93 & 0.96 & & & & 0.13 & 88.1 & 86.0 \\
\hline $6 / 24 / 94$ & BVं-473 & Blacksville & 63.0 & 130.2 & 50 & 20 & 7.0 & 4.8 & 5.58 & 0.88 & 3.48 & 2.6 & 2.75 & 0.13 & 0.24 & 93.5 & 84.8 \\
\hline $6 / 24 / 94$ & BV-473 & Blacksville & 52.0 & 129.7 & 45 & 60 & 7.0 & 6.2 & 6.00 & 0.69 & 3.90 & & & & 0.11 & 97.3 & 78.3 \\
\hline $7 / 6 / 94$ & BB-384 & $\begin{array}{l}\text { Big Brown } \\
\text { (conditioned) }\end{array}$ & 37.0 & 130.7 & 50 & 60 & 7.0 & 2.0 & 1.40 & 0.96 & 2.52 & 2.8 & 3.05 & 0.26 & 0.23 & 91.6 & 283.6 \\
\hline $7 / 6 / 94$ & BB-384 & $\begin{array}{l}\text { Big Brown } \\
\text { (conditioned) }\end{array}$ & 27.0 & 130.7 & 47 & 20 & 7.0 & 6.2 & 3.15 & 0.91 & 2.17 & & & & 0.26 & 89.3 & 106.0 \\
\hline
\end{tabular}


TABLE 7

APS and CPC Statistical Data

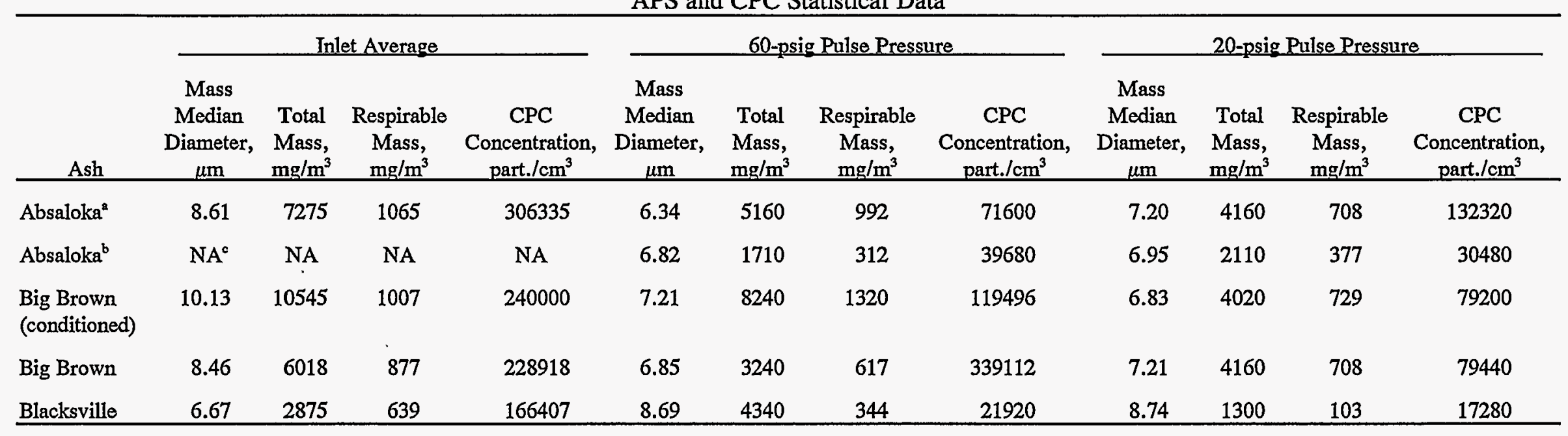

7-in. W.C. pressure drop.

$\sim \quad{ }^{b} 2$-in. W.C. pressure drop.

${ }^{\circ}$ Not available. 

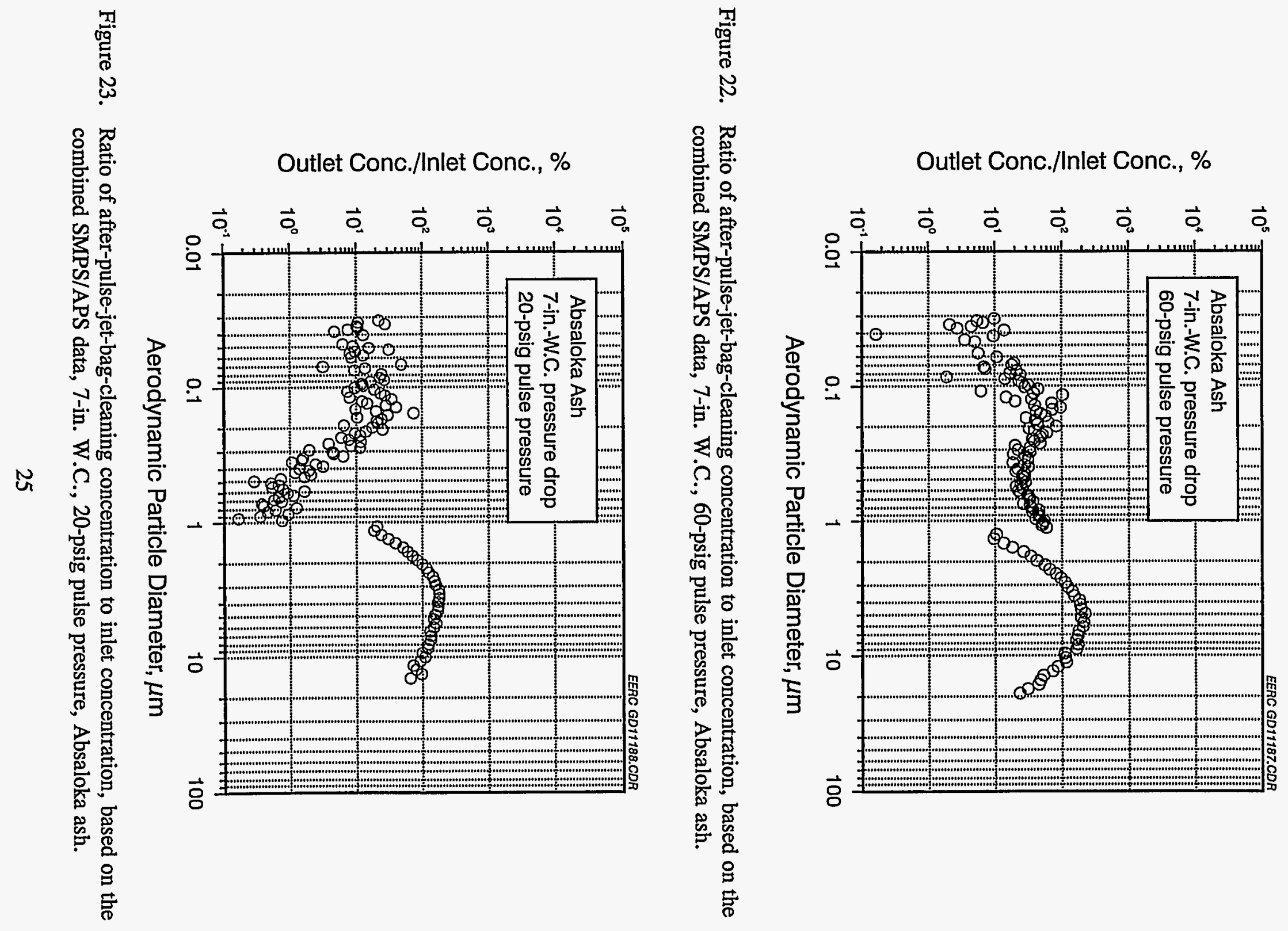


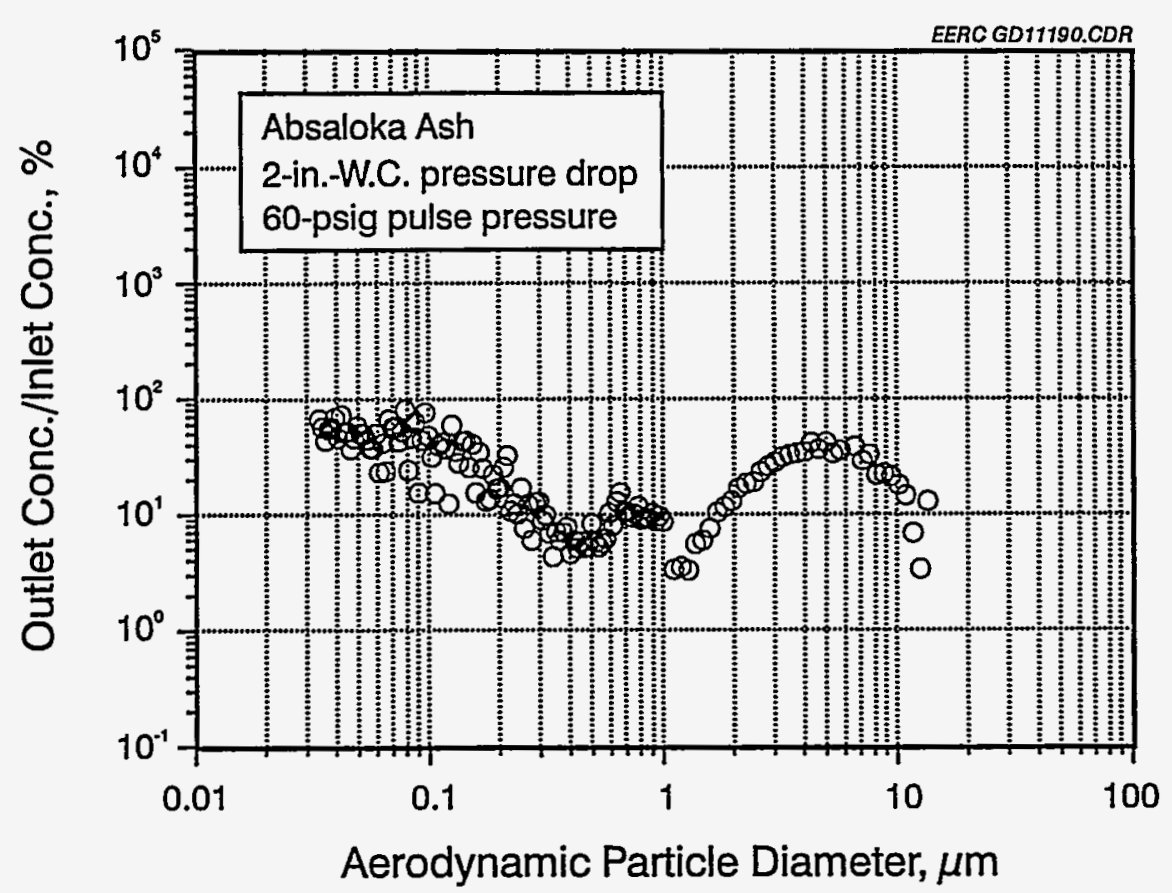

Figure 24. Ratio of after-pulse-jet-bag-cleaning concentration to inlet concentration, based on the combined SMPS/APS data, 2-in. W.C., 60-psig pulse pressure, Absaloka ash.

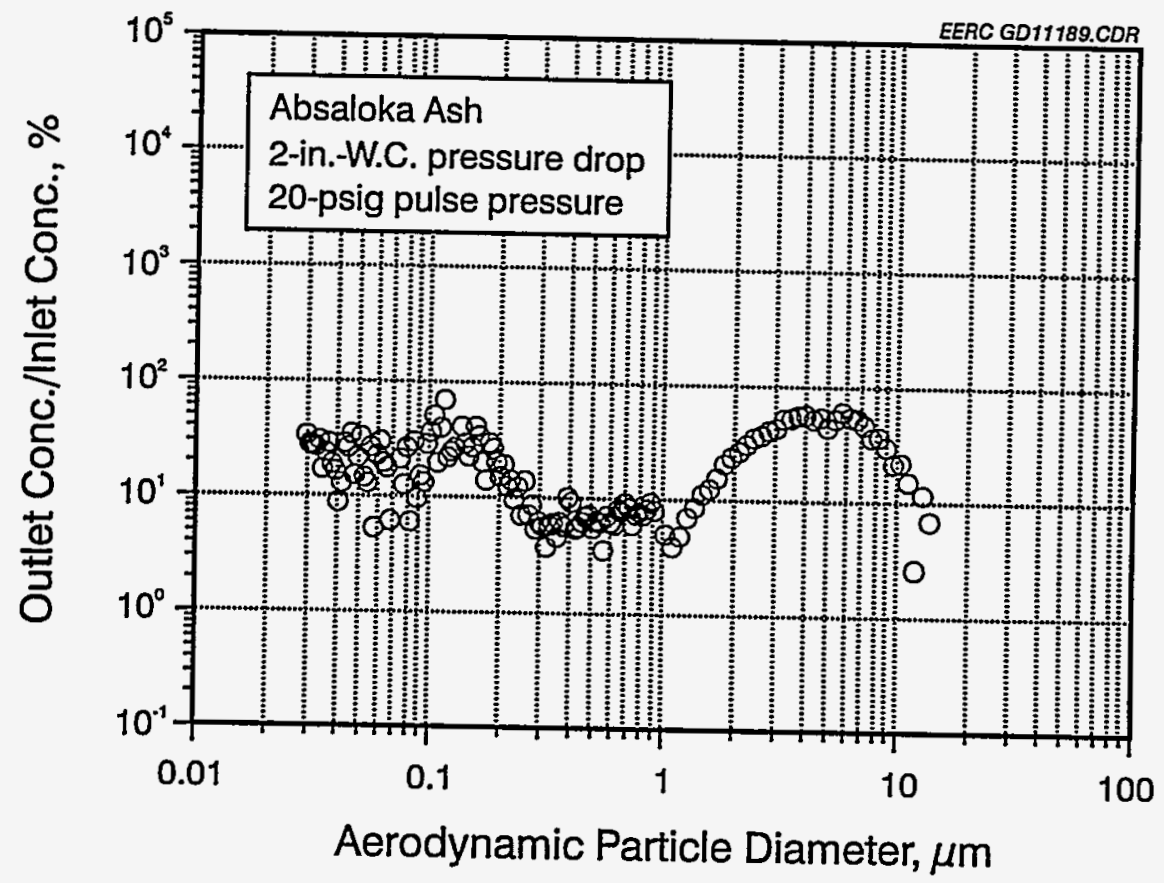

Figure 25. Ratio of after-pulse-jet-bag-cleaning concentration to inlet concentration, based on the combined SMPS/APS data, 2-in. W.C., 20-psig pulse pressure, Absaloka ash. 


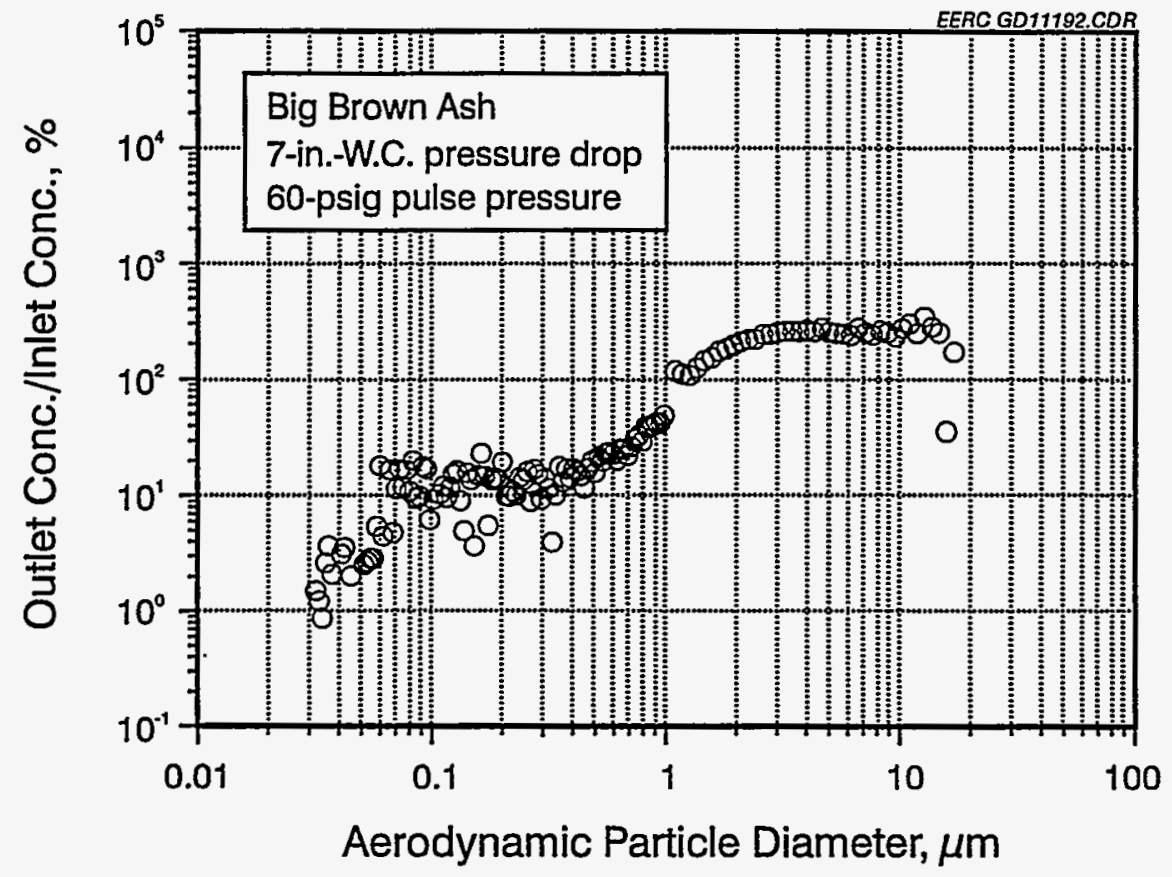

Figure 26. Ratio of after-pulse-jet-bag-cleaning concentration to inlet concentration, based on the combined SMPS/APS data, 7-in. W.C., 60-psig pulse pressure, baseline Big Brown ash.

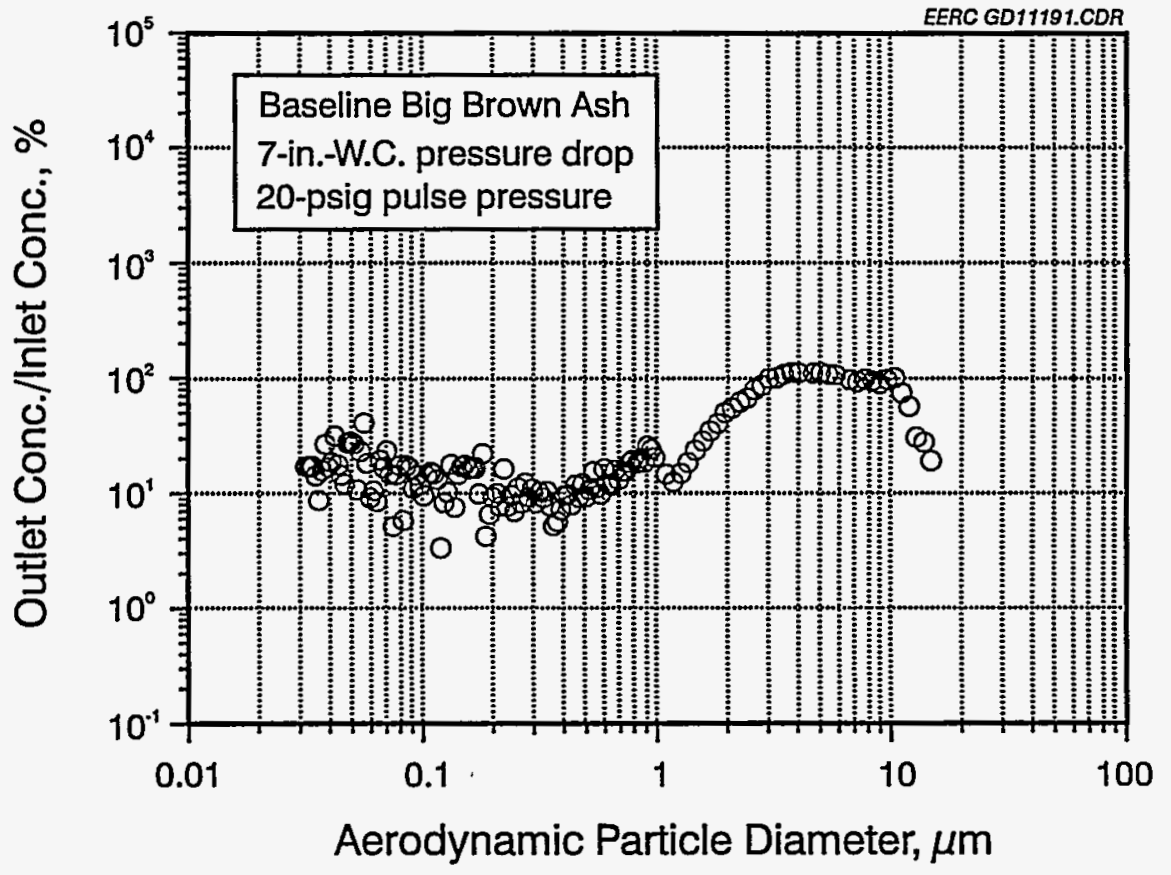

Figure 27. Ratio of after-pulse-jet-bag-cleaning concentration to inlet concentration, based on the combined SMPS/APS data, 7-in. W.C., 20-psig pulse pressure, baseline Big Brown ash. 


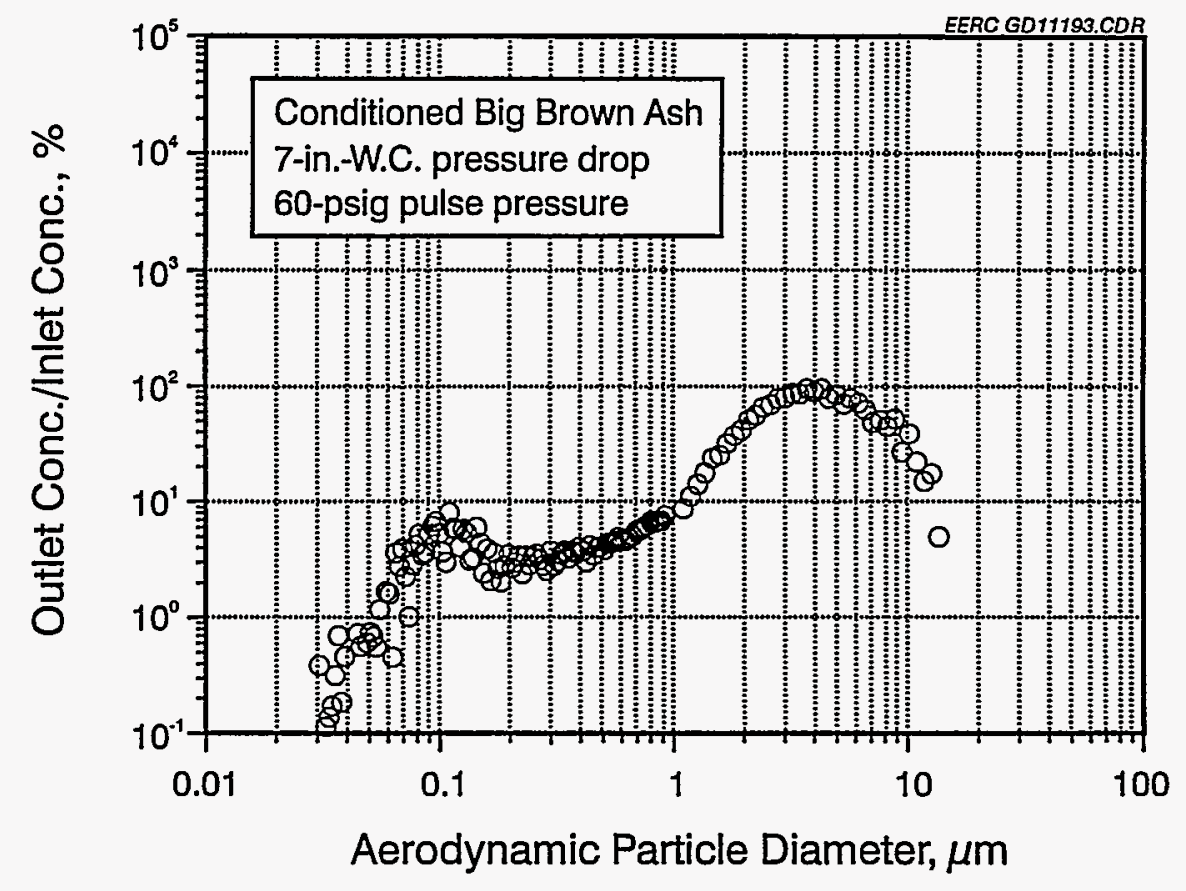

Figure 28. Ratio of after-pulse-jet-bag-cleaning concentration to inlet concentration, based on the combined SMPS/APS data, 7-in. W.C., 60-psig pulse pressure, conditioned Big Brown ash.

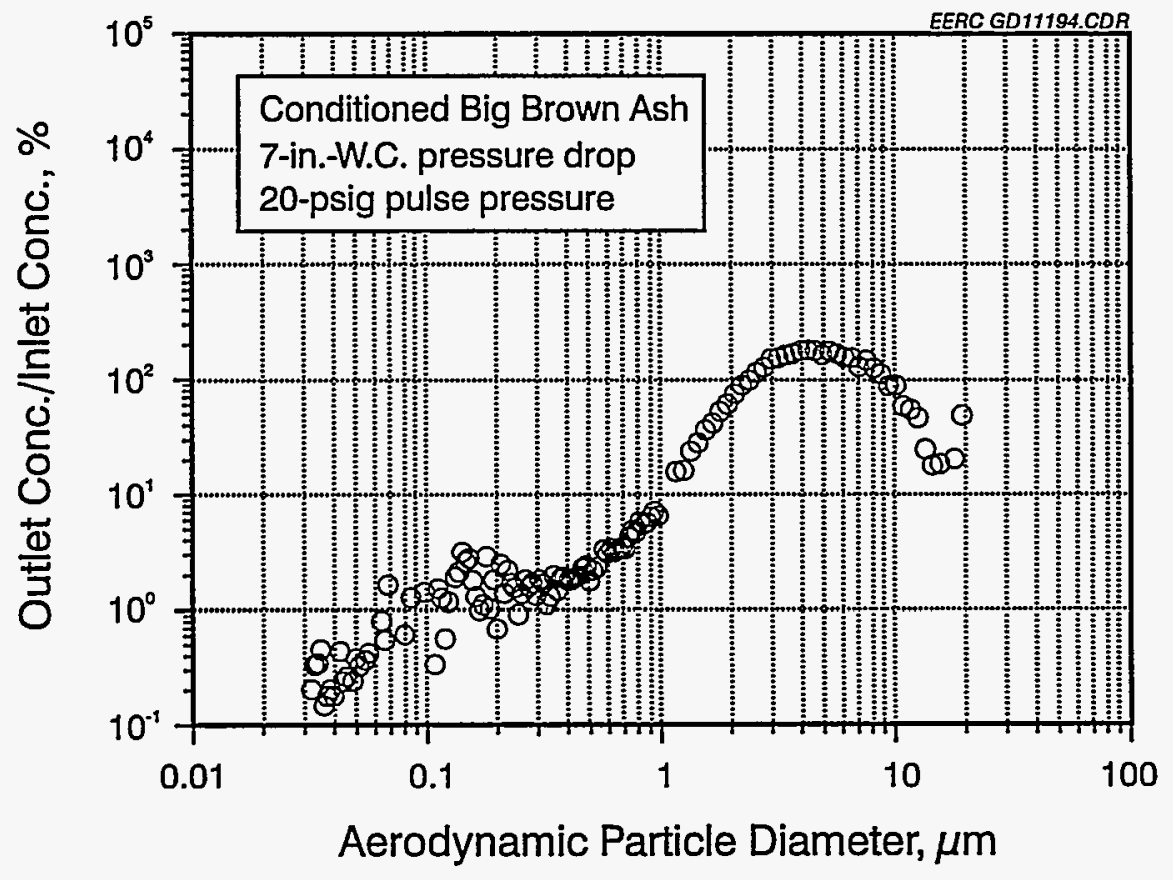

Figure 29. Ratio of after-pulse-jet-bag-cleaning concentration to inlet concentration, based on the combined SMPS/APS data, 7-in. W.C., 20-psig pulse pressure, conditioned Big Brown ash. 


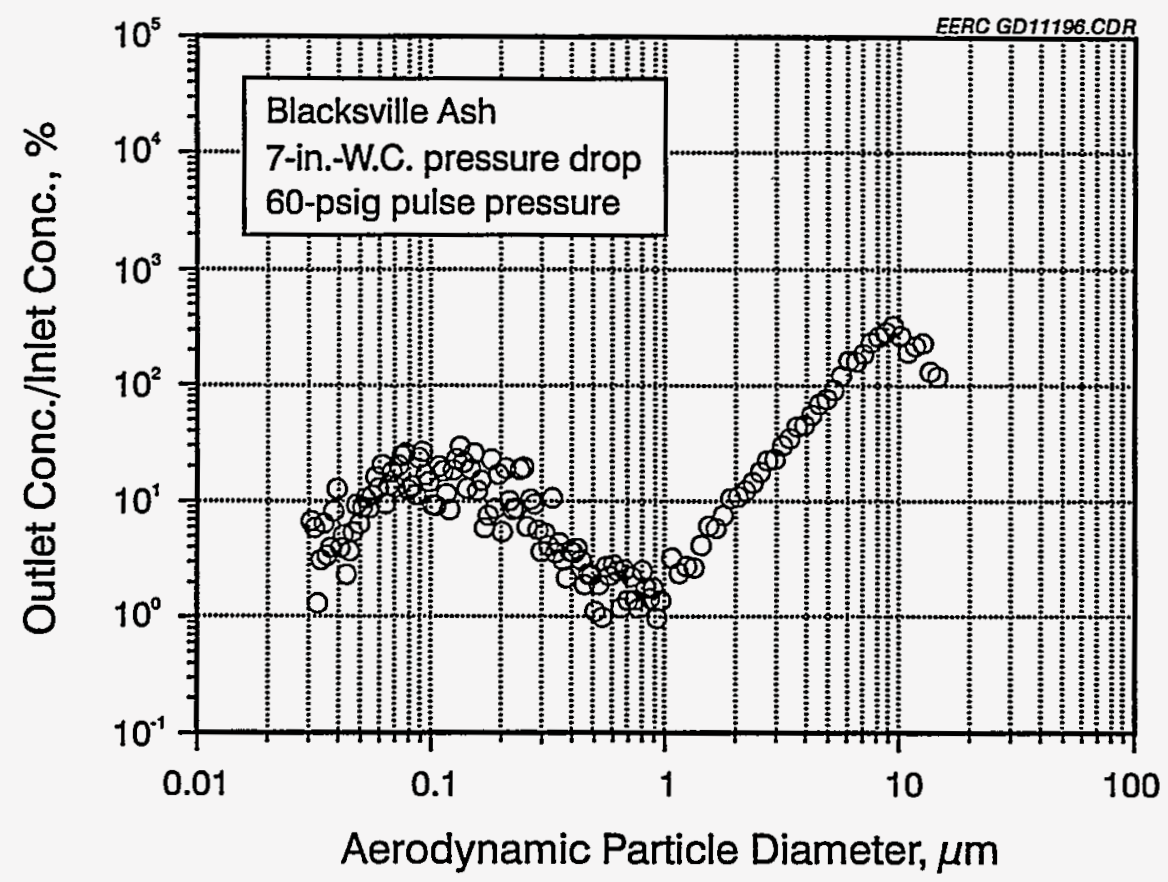

Figure 30. Ratio of after-pulse-jet-bag-cleaning concentration to inlet concentration, based on the combined SMPS/APS data, 7-in. W.C., 60-psig pulse pressure, Blacksville ash.

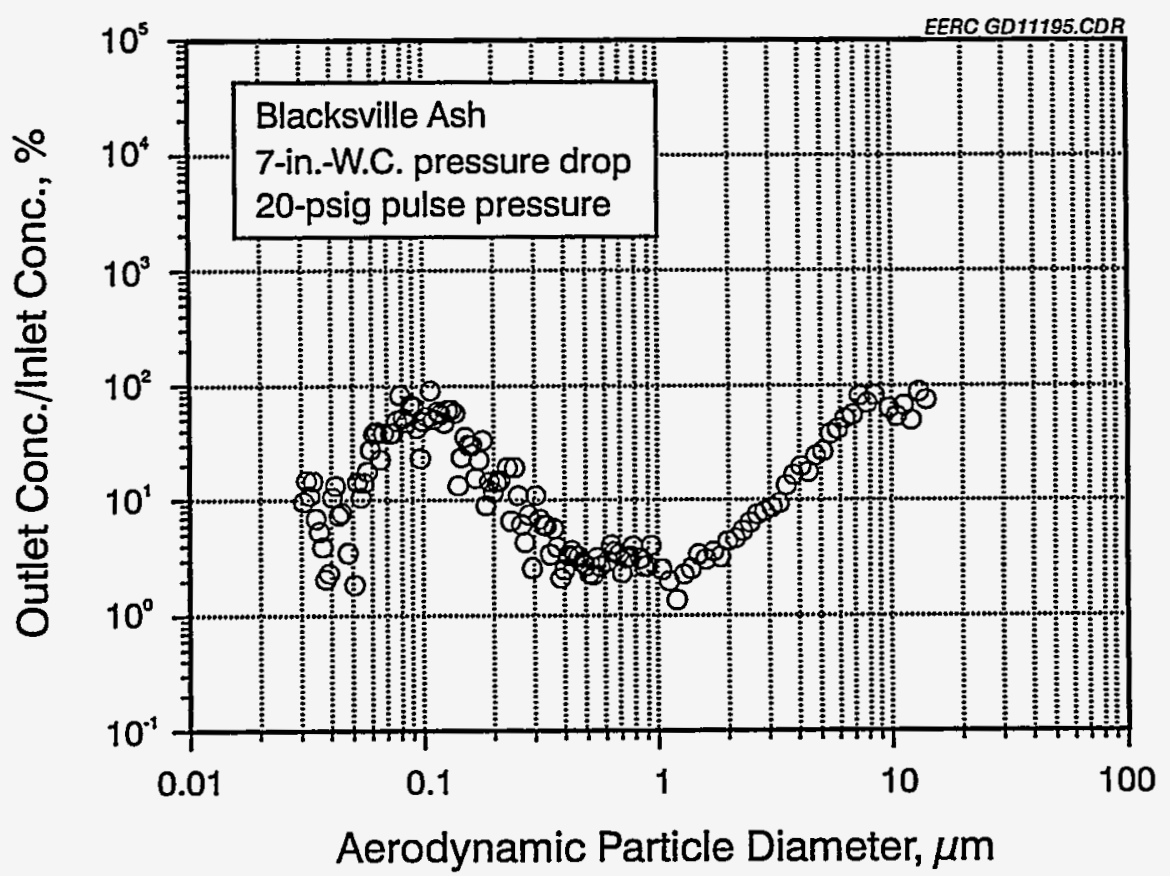

Figure 31. Ratio of after-pulse-jet-bag-cleaning concentration to inlet concentration, based on the combined SMPS/APS data, 7-in. W.C., 20-psig pulse pressure, Blacksville ash. 
Video equipment was used to record the pulsing of the bag. The video shows ash was removed from the entire bag, from the top and down the length of the bag. Most of the ash that was removed fell to the hopper as large agglomerates. The video also showed the ash cloud disperse and become more dilute shortly after the bag was pulsed. The particle concentration data are consistent with this observation.

From the data, the injected ash was apparently redispersed adequately for determining the level of ash reentrainment when a filter or an ESP plate was cleaned. The difference in size distribution due to ash type was not as pronounced as expected. This lack of dependence on ash type is likely a limitation of the ash injection system, since the tensile strength data indicate that the ashes do have somewhat different cohesive properties. The mass balance data indicated that the ash type and the ash layer thickness did not affect the percent of the collected ash removed from the collection device during cleaning. It is expected this is a function of the cleaning energy. While the ESP cleaning energy was constant, the low-level baghouse cleaning energy may have been high enough to adequately remove the ash from the bag, and the higher level of cleaning energy provided no additional cleaning benefit. The ash layer thickness did not seem to affect the ESP test results.

A number of concerns exist with the size distribution of the ash on the ESP plate or pulse-jet bag. What was the size distribution of the ash on the ESP plate or pulse-jet bag, and what effect did it have on the size distribution of the redispersed ash? We know the ash on the bottom third of the ESP plate will have a higher concentration of larger particles, but to what degree we do not know. Was the lack of submicron particles in the redispersed ash due to poor collection efficiency of the submicron particles or to the agglomeration of the submicron particles to form larger particles? The collection efficiencies of both collection devices are high for the submicron particles; therefore, the decrease in submicron particles and the increase in particles $>1 \mu \mathrm{m}$ is because of agglomeration. What is the effect of the sampling location on the distributions after cleaning of the collection devices? The differences observed between the ESP and the baghouse data may be the result of the sampling locations. The sampling point in the ESP was roughly 2 feet below the plate and roughly 3 feet above the hopper. In the baghouse, the sampling point was roughly 1 foot below the bottom of the bag and 8 feet above the hopper. The ESP data may include a "puff" from the hopper that the baghouse does not, therefore a comparison of the data from the two systems would not be valid.

\subsection{CONCLUSIONS/RECOMMENDATIONS}

Based on tensile strength measurements, the ashes were expected to be redispersed to unique size distributions, but it appears the injection system was not capable of redispersing the ashes to different size distributions. This interfered with the ability to distinguish the effect of ash type, but did not affect the other test variables. A concern with injecting ash was the ability to redisperse enough ash particles in the submicron region to evaluate the effects of ESP or filter cleaning on the reentrainment of ash. However, based on multicyclone data and SMPS data, adequate quantities of each ash were redisbursed into the submicron region.

For the ESP reentrainment tests, ash type does not appear to have any effect on the size distribution or concentration of submicron particles. This may be a deficiency in the ash injection system. The data do indicate that the ash was redispersed as larger particles when the ESP plate was rapped, most likely because of the agglomeration of smaller particles that did not redisperse when the 
plate was rapped. The extent of agglomeration increases with decreasing particle size. There does appear to be a difference due to ash layer thickness. The thicker ash layer redispersed to a larger size distribution than the thinner ash layer. The mass balance data indicate that the ash with the highest tensile strength (Blacksville) was the easiest to remove from the plate and the ash with the lowest tensile strength (baseline Big Brown) was the most difficult. The comparison of inlet particulate concentrations to concentrations after rapping the ESP plate indicate that the ash was redispersed to concentrations lower than those found in the inlet in the submicron region and higher for larger particles. This also indicates agglomeration of the smaller particles. 



\section{Original Camera Ready Copy}

